\title{
Measurements of Raindrop Size Distributions over the Pacific Warm Pool and Implications for $Z-R$ Relations
}

\author{
SANDRA E. Yuter And Robert A. Houze JR.
}

(Manuscript received 23 January 1996, in final form 12 November 1996)

\begin{abstract}
Raindrop images obtained on research flights of the NCAR Electra aircraft in the Tropical Oceans Global Atmosphere Coupled Ocean-Atmosphere Response Experiment (TOGA COARE) are analyzed. The drop size distributions, based on the images obtained in 6-s samples (about $750 \mathrm{~m}$ of flight track), are used to calculate both radar reflectivity $Z$ and rain rate $R$. Airborne radar data from the NOAA P-3 aircraft flying in coordination with the Electra are used to categorize the particle-image data according to whether the drop images were obtained in regions of convective or stratiform precipitation.

Within stratiform precipitation, the same rain rate could be produced by a drop spectrum dominated by numerous small drops (lower reflectivity) or by a few large drops (higher reflectivity). The reflectivity values varied by as much as $9 \mathrm{~dB}$ for a given rain rate. Reflectivity data from the airborne radar and flight-level data reveal that the stratiform regions often contain fallstreaks of about $0.1-2 \mathrm{~km}$ in horizontal dimension. The fallstreaks are associated with large-drop spectra and local maxima in reflectivity up to approximately $40 \mathrm{dBZ}$ and in rain rates up to $25 \mathrm{~mm} \mathrm{~h}^{-1}$. The fallstreaks extend downward from the melting band and bend with the low-level wind shear, but do not usually reach the surface. Thus, although relatively more uniform than convective regions, stratiform regions can be variable in reflectivity and rain rate at fine spatial scales in both the horizontal and vertical directions. Stratiform regions are therefore best characterized by their ensemble properties rather than the values of individual high-resolution measurements.

The variability of stratiform drop size spectra arises primarily from the occurrence of fallstreaks and the discontinuous nature of regions favoring aggregation of snow crystals, and it implies that $Z-R$ distributions associated with convective and stratiform precipitation are not statistically distinct. Thus, separate $Z-R$ relations for convective and stratiform precipitation are not justified, and techniques to distinguish between convective and stratiform precipitation based solely on the characteristics of drop size distributions are not likely to be accurate.

The variability of the drop size spectra in tropical precipitation makes an exponential fit to the $Z-R$ relation sensitive to the spatial scale over which $Z$ and $R$ are determined. This sensitivity can be avoided by using a probability-matched $Z-R$ relation. The probability-matched $Z-R$ relation for all the raindrop image data from the Electra collected between altitudes of 2.7 and $3.3 \mathrm{~km}$ in TOGA COARE is similar to the $Z-R$ relation obtained at the sea surface in the Global Atmospheric Research Program Atlantic Tropical Experiment.
\end{abstract}

\section{Introduction}

Accurate measurement of rainfall in the Tropics is of fundamental importance to studies of the earth's climate. However, the ability to obtain such measurements over broad areas remains illusory. Rain gauges, distrometers, ${ }^{1}$ and particle-image probes ${ }^{2}$ measure rain directly,

\footnotetext{
${ }^{1}$ A distrometer is deployed at the earth's surface and measures the number of raindrops in a series of size ranges falling on a horizontal surface in a finite period of time. A commonly used distrometer is that designed by Joss and Waldvogel (1967).

${ }^{2}$ A particle-image probe is usually mounted on aircraft, where it detects the two-dimensional images of particles in an illuminated vertical plane.
}

Corresponding author address: Dr. Sandra E. Yuter, Dept. of Atmospheric Sciences, University of Washington, Box 351640, Seattle, WA 98195.

E-mail: yuter@atmos.washington.edu but only at the location of the instrument, and thus they are impractical for obtaining the distribution of rain over large areas. Characteristics of precipitating clouds, such as microwave irradiance, cloud-top infrared irradiance, and radar reflectivity, can be measured remotely over large regions by sensors on satellites, aircraft, ships, and on the ground. The information from these indirect measurements of precipitation must be converted to the rain rate by using an appropriate algorithm. Although the basic physics behind these algorithms may be understood, algorithm parameters typically must be calibrated to the particular rain regime under study in order to produce accurate results. Often the approach to calibration is one of bootstrapping - using a small-scale direct measurement to calibrate a larger-scale indirect measurement, which in turn is used to calibrate a still largerscale measurement successively until the scale needed is reached. Thus, it is vital that the initial relation upon which this sequence of calibrations is based be as accurate as possible. 


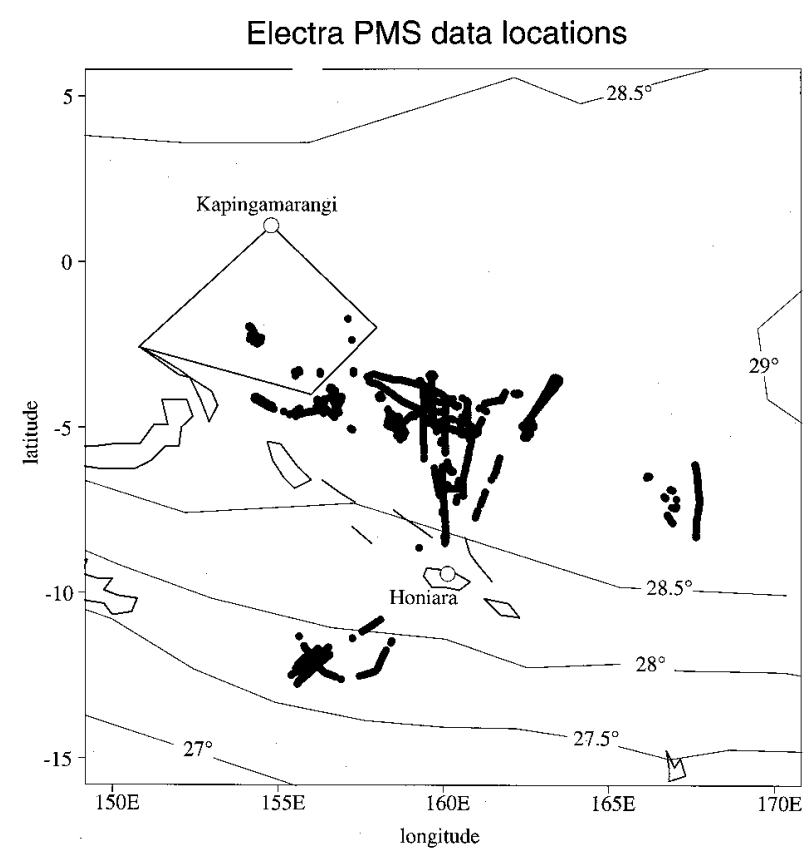

FIG. 1. Geographic distribution within the TOGA COARE region of Electra PMS samples used in this study. The polygon centered near $2^{\circ} \mathrm{S}, 156^{\circ} \mathrm{E}$ is the intensive flux array. Contours of mean IOP sea surface temperature $\left({ }^{\circ} \mathrm{C}\right)$ indicate the location of the warm pool (time-averaged National Centers for Environmental Prediction global SST analysis provided by S. Chen). The locations of Honiara, Guadalcanal, the Solomon Islands (the turboprop aircraft base), and $\mathrm{Ka}-$ pingamarangi Atoll, Federated States of Micronesia, at the northern tip of the IFA are indicated.

The calibration sequence is often built upon a relation between radar reflectivity and rain rate. From 1 November 1992 to 28 February 1993, during the intensive observation period (IOP) of the Tropical Oceans Global Atmosphere Coupled Ocean-Atmosphere Response Experiment (TOGA COARE), numerous instruments were deployed over the large-scale pool of warm water covering the tropical western Pacific Ocean. These instruments documented the clouds and precipitation over the warm pool and their interaction with the atmospheric boundary layer and the upper ocean (Webster and Lukas 1992). Among these observations were airborne and shipborne radar measurements of precipitation. The shipborne radar measurements aim to provide quantitative estimates of the precipitation in the domain of intensive observations [the TOGA COARE intensive flux array (IFA)]. An important objective, therefore, is to determine the relationship between the measured radar reflectivity $Z$ and the rain rate $R$.

Both radar reflectivity and rain rate can be computed from measurements of raindrop size spectra. In TOGA COARE, a distrometer located on the atoll of Kapingamarangi, on the northern extremity of the IFA (Fig. 1), made measurements of the size distribution of raindrops. Tokay and Short (1996) have studied these atollbased data. Measurements of the raindrop size distri- bution were also made by particle-image probes onboard the National Center for Atmospheric Research (NCAR) Electra aircraft. These aircraft measurements were made over a wide region of the warm pool in precipitation similar to that observed by the ship radars (Fig. 1). In this study, we use the airborne drop size data to investigate the $Z-R$ relationship for the western Pacific warmpool region. Such a relationship is needed in order to use the reflectivity data collected by the shipboard radars in TOGA COARE to estimate rain patterns.

The precipitation in major tropical cloud systems has a large stratiform component as well as a convective component (Houze 1989; Mapes and Houze 1995). Tokay and Short (1996) found that the drop size distributions measured at Kapingamarangi fell into two distinguishable groups: one dominated by small drops and the other dominated by large drops. They suggested that these groupings of the data arise from the convective and stratiform portions of the rainfall, respectively. In this study, we find that the drop size distributions sampled by aircraft also tend to fall into two groups, but that these groups do not correspond to convective and stratiform precipitation-rather, that stratiform precipitation itself may contain both large- and small-drop distributions. To arrive at this conclusion, we analyze all of the drop size distributions sampled by the Electra aircraft at altitudes of about $3 \mathrm{~km}$, and we use radar data from the National Oceanic and Atmospheric Administration (NOAA) WP-3D (P-3) aircraft, when it was flying coordinated missions with the Electra, to determine whether the Electra was sampling particle images in convective or stratiform radar echo.

\section{Data}

\section{a. Particle-image probe}

The particle-image probe on the NCAR Electra aircraft was a Particle Measuring System Inc. (PMS) 2D precipitation monoprobe, which detects particles in the diameter range of $0.2-6.4 \mathrm{~mm}$. Data obtained by the probe were accumulated over 6-s intervals, each representing approximately $750 \mathrm{~m}$ of flight track and an average volume of about $1400 \mathrm{~L}$. The PMS probes onboard the Electra were mounted near the wing tip such that a laser light beam illuminated a vertical plane oriented parallel to the flight track. Particles passing between the laser source and an array of light detectors occult the beam, producing an image of the particle. The probe was calibrated approximately once a month with a spinning disk etched with calibrated images (D. Baumgardner 1995, personal communication).

The initial steps in the PMS data processing were performed by R. Black of NOAA/Atlantic Oceanographic and Meteorological Laboratory/HRD (Hurricane Research Division) (see appendix A for details). After receiving the data from NOAA, further processing was performed. Postproject-calibrated 1-s Electra flight- 
TABLE 1. Electra missions in which PMS data were collected between 2.7- and 3.3-km altitude. Mission date is UTC date on takeoff. Location is the approximate center of the mission area. Surface wind direction is from synoptic analysis of Bond and Alexander (1994) The cloud systems investigated by the aircraft are categorized by mission class according to the cloud systems' contiguous area of infrared cloud top colder than $208 \mathrm{~K}$, following Mapes and Houze (1992). Class 4-larger than $60000 \mathrm{~km}^{2}$, class 3-between 20000 and $60000 \mathrm{~km}^{2}$, class 2-between 6000 and $20000 \mathrm{~km}^{2}$, class 1 -less than $6000 \mathrm{~km}^{2}$, and class 0 -no clouds with IR temperatures less than $208 \mathrm{~K}$.

\begin{tabular}{rlllc}
\hline \hline & & & Seg- \\
& & & & ments \\
clas- \\
sified
\end{tabular}

level data provided by NCAR were used to retain only those data obtained when the aircraft was between altitudes of 2.7 and $3.3 \mathrm{~km}$. Samples collected when the aircraft was only partially within precipitation over the 6-s interval (sample volume less than $1000 \mathrm{~L}$ ) were deleted from the dataset. A total of 7022 6-s samples of PMS data meeting these criteria were collected during 29 Electra missions over a wide area (Fig. 1) and within a variety of large-scale atmospheric conditions (Table 1). An additional quality control step removed spurious counts of unknown origin in bin sizes larger than $4 \mathrm{~mm}$. Since true drop size spectra usually contain data in contiguous bins, data in bin sizes larger than $4 \mathrm{~mm}$ were rejected when the sum of the counts in bin sizes from 3 to $4 \mathrm{~mm}$ within the same sample was zero. Spurious counts of this nature were removed from about $4 \%$ of the samples. To characterize the vertical motions associated with the drop spectra, corrected NCAR Electra flight-level data obtained at 1-s intervals were averaged over 6-s intervals to compute the flight-level vertical velocity associated with the 6-s PMS data samples.

Radar reflectivity factor $Z\left(\mathrm{~mm}^{6} \mathrm{~m}^{-3}\right)$ and rain rate $R$ $\left(\mathrm{mm} \mathrm{h}^{-1}\right)$ were computed as follows from the qualitycontrolled drop spectra:

$$
Z=1000 \sum_{i=1}^{32} n_{i} D_{i}^{6}
$$

and

$$
R=6000 \pi \sum_{i=1}^{32} n_{i} D_{i}^{3} V\left(D_{i}\right),
$$

where $D_{i}$ is the diameter ( $\mathrm{mm}$ ) corresponding to the $i$ th bin in the histogram of the drop spectrum, $n_{i}$ is the number of drops in that bin, and $V\left(D_{i}\right)$ is the fall speed $\left(\mathrm{cm} \mathrm{s}^{-1}\right)$ of the drops according to the empirical formula of Gunn and Kinzer (1949). For presentation, the radar reflectivity factor is converted to decibel units of radar reflectivity, with $\mathrm{dBZ}=10 \log _{10} Z$. Note that (1) and (2) determine $Z$ and $R$ directly from the measured drop size spectrum; they require no assumption that the spectrum has any particular form (e.g., exponential). Note also that radar reflectivity is calculated from the measured drop sizes; it is not measured by a radar. Radar data are used in this study only to determine the structure of the radar echoes within which the particle size spectrum is measured.

At certain stages of storm evolution, a few large drops may dominate the raindrop size distribution (large-drop spectra), while at other times, numerous small drops are more common (small-drop spectra; Waldvogel 1974; Austin 1987). Since radar reflectivity is more sensitive to drop diameter than rain rate [(1) and (2)], the same rain rate can be produced by many small drops, producing a lower reflectivity, or a few larger drops, producing a higher reflectivity. We refer to a drop size spectrum producing a low (high) reflectivity at a given rain rate as a "small (large)-drop distribution."

\section{b. Radar}

Data from five airborne radars are employed (Table 2). The horizontal structure of radar echoes is indicated by lower-fuselage (LF) radars on the two NOAA P-3 aircraft $(N 42 R F$ and $N 43 R F)$. Both NOAA P3 aircraft are instrumented with a C-band (5-cm wavelength) LF radar, which scans horizontally at a small elevation angle to minimize the intersection of the beam with the ocean surface. The vertical width of the beam of the LF radar is large $\left(4.1^{\circ}\right)$. Thus, depending on aircraft altitude, the radar reflectivity values at longer ranges may include backscatter from above, within, and below the $0^{\circ} \mathrm{C}$ level, making the comparison of absolute reflectivities at different ranges ambiguous. However, the horizontal beam- 
TABLE 2. Selected characteristics of airborne radars used in this study.

\begin{tabular}{|c|c|c|c|}
\hline & $\begin{array}{l}\text { NOAA P-3 } \\
\text { lower- } \\
\text { fuselage } \\
\mathrm{C} \text { band }\end{array}$ & $\begin{array}{l}\text { NOAA P-3 } \\
\text { tail radar } \\
\mathrm{X} \text { band }\end{array}$ & $\begin{array}{c}\text { NCAR } \\
\text { ELDORA } \\
\text { tail radar } \\
\mathrm{X} \text { band }\end{array}$ \\
\hline $\begin{array}{l}\text { Wavelength }(\mathrm{cm}) \\
\text { Peak transmitted }\end{array}$ & 5.59 & 3.22 & 3.2 \\
\hline $\begin{array}{l}\text { Power }(\mathrm{kW}) \\
\text { Beamwidth }\left(^{\circ}\right)\end{array}$ & 70 & 60 & 35 \\
\hline $\begin{array}{l}\text { Horizontal } \\
\text { Vertical } \\
\text { Pulse length }(\mathrm{km})\end{array}$ & $\begin{array}{l}1.1 \\
4.1 \\
0.9\end{array}$ & $\begin{array}{l}1.35 \\
1.9 \\
0.075\end{array}$ & $\begin{array}{l}1.8 \\
1.8 \\
0.15\end{array}$ \\
\hline $\begin{array}{l}\text { Antenna rotation } \\
\text { rate }\left({ }^{\circ} \mathrm{s}^{-1}\right)\end{array}$ & $\begin{array}{l}6 \\
\text { Horizontal }\end{array}$ & $\begin{array}{l}60 \\
\text { Vertical }(N 42 R F)\end{array}$ & 66 \\
\hline Polarization & Horizontal & $\begin{array}{l}\text { Vertical }(N 42 R F) \\
\text { Horizontal }(N 43 R F)\end{array}$ & Horizontal \\
\hline
\end{tabular}

width of the LF radar is small $\left(1.1^{\circ}\right)$, permitting detailed mapping of the horizontal pattern of reflectivity. We constructed maps of the P-3 lower-fuselage radar reflectivity for all times that the Electra aircraft was within $120 \mathrm{~km}$ of a P-3 aircraft and the P-3 was flying straight and level. Each map is a composite of the reflectivity measurements obtained during a 5-min segment of the P-3 flight track. The radar measurements obtained during each 5 min were interpolated ${ }^{3}$ to a $2 \mathrm{~km} \times 2 \mathrm{~km}$ horizontal grid. We call each 5-min radar reflectivity map an "LF composite."

The detailed vertical structure of radar echoes is indicated by X-band (3-cm wavelength) tail radars onboard the NOAA and NCAR aircraft. The tail radars map reflectivity and Doppler radial velocity at fine resolution in the vertical with scanning cones tilted approximately $\pm 20^{\circ}$ perpendicular to the aircraft heading $\left(20^{\circ}\right.$ from vertical; Hildebrand et al. 1994). The X-band tail radars are severely attenuated in heavy rain, so that their effective range is usually limited to less than 40 $\mathrm{km}$. The Electra tail radar data are recorded in range bins $0.15 \mathrm{~km}$ wide. The beamwidth is $1.8^{\circ}$, so the effective spatial resolution is about $1.3 \mathrm{~km}$ at the farthest useful range $(40 \mathrm{~km})$. The $\mathrm{P}-3$ tail radar data are similar. The two NOAA P-3 aircraft flew a total of 25 missions over the 4-month IOP (Yuter et al. 1995). During a subset of those missions, the P-3 aircraft operated in proximity to the NCAR Electra. Research quality data are available from the Electra Doppler radar (ELDORA) tail radar for several missions in February 1993.

\section{Methods of analysis}

a. Definition of convective and stratiform precipitation

This study analyzes the similarities and differences between raindrop size distributions in convective and

\footnotetext{
${ }^{3}$ The software used to perform the interpolation of the aircraft LF data is called INTERPOL; its original version was written by B. Mapes.
}

stratiform precipitation. The nature of the precipitation field in a region of the atmosphere reflects the nature of the vertical air motions in that region. When the intensity of the precipitation exhibits strong variability in the horizontal and radar echoes consist of vertical columns of high reflectivity, the air is usually in a state of convection characterized by strong up- and downdrafts, which act to homogenize the vertical distribution of moist static energy in the atmosphere. In such situations, the air contains up- and downdrafts of about 1$10 \mathrm{~m} \mathrm{~s}^{-1}$, and we refer to the horizontally variable precipitation seen on radar as "convective precipitation." Houghton (1968) pointed out that the primary precipitation-growth process in convective precipitation is a collection of cloud water by precipitation particles in the strong updraft cores. Convective up- and downdrafts are usually $1-6 \mathrm{~km}$ in dimension (Yuter and Houze 1995a). Typically, several updraft-downdraft pairs occur in the same general vicinity and produce a horizontally variable precipitation pattern over an area approximately $10-100 \mathrm{~km}$ in horizontal dimension. We refer to such a pattern of precipitation as a "convective region."

When the intensity of the precipitation over an area approximately $10-100 \mathrm{~km}$ in horizontal dimension exhibits less variability in the horizontal and the radar reflectivity field appears to be in layers, the precipitation is typically referred to as "stratiform." The upward air motions sustaining stratiform precipitation are weaker $\left(\sim 1-10 \mathrm{~cm} \mathrm{~s}^{-1}\right)$ but more widespread than the locally strong up- and downdrafts in regions of convective precipitation. Thus, the fall speeds of the precipitating ice particles $\left(\sim 1-2 \mathrm{~m} \mathrm{~s}^{-1}\right.$; Locatelli and Hobbs 1974) far exceed the magnitude of the vertical air motion. Houghton (1968) pointed out that under these conditions the primary precipitation-growth process is vapor deposition on ice particles, a slow process, and particles must fall from near cloud top to attain the maximum possible growth by vapor diffusion. Stratiform precipitation areas are thus distinct from convective areas by virtue of particles always settling downward and growing slowly by deposition of vapor, in contrast to the convective updraft cores, in which large concentrations of droplets condense rapidly and are readily available for collection by larger precipitation particles.

When a convective updraft weakens, many ice particles grown by collection of cloud droplets and carried up to the top of the cell during the active phase of the convective updraft slowly fall out through the weaker upward motion, while continuing to grow by vapor diffusion. The once-convective precipitation core thus turns into a region of stratiform precipitation. The weakening of convective cells appears to account for a large portion of the stratiform-appearing radar echo over the tropical ocean. In this sense, the designation stratiform does not imply that the precipitation was not convective in origin, but rather that the dominant air motions and precipitation growth processes have changed over from 
the collection-dominated vertical columns of strong radar echo to the vapor-diffusion-dominated broad layers characterized by downward drifting ice particles formed earlier in updrafts but left aloft as the upper regions of convective updrafts weaken. As the parcels of air in the convective updrafts rise out of the boundary layer and reach the upper atmosphere, they broaden and flatten as a result of decreasing pressure and of reaching their level of neutral buoyancy (Lilly 1988; Yuter and Houze 1995c). As progressively more weakened, spreading convective elements congregate in the upper troposphere, they amalgamate to form a large horizontal area, which we identify as the stratiform region on radar.

\section{b. Identification of convective and stratiform portions of a radar echo}

It is difficult to locate regions of atmospheric convection because direct measurements of the vertical air motion are rarely available to indicate those areas in which air is actively overturning. Willis et al. (1995) have suggested that the variance of 6-m spatial scale $(20 \mathrm{~Hz})$ vertical air motions sampled by aircraft over $750 \mathrm{~m}$ of flight track can be used to classify whether that $750-\mathrm{m}$ interval lies in a convective or stratiform region. However, since the scale of radar-detectable irregularities in precipitation (and air motion) patterns is usually $2-5 \mathrm{~km}$ and the scale of a convective region detected by radar is typically $10-100 \mathrm{~km}$ in dimension, the existence of a few highly localized spikes of vertical velocity along a particular 750-m line segment (producing a high variance in that segment) only indicates that the segment may lie somewhere within a larger region of convective overturning. However, it also may lie in a stratiform region; in section 4, we show that stratiform regions contain small-scale variability that is greatly reduced when the data are filtered to 2- or 4-km resolution. Furthermore, the absence of spikes of vertical velocity along a 750-m fight segment does not indicate that the segment is not within a larger region of convective overturning. A convective region is not filled everywhere with strong up- and downdrafts (Yuter and Houze 1995b,c). Rather, it is a region approximately $10-100 \mathrm{~km}$ in dimension in which strong local updrafts, generally larger in scale than $750 \mathrm{~m}$, occur intermittently and sporadically. The 750-m segments of high variance, of the type detected by the method of Willis et al. (1995), are thus not present everywhere in a region of convective overturning.

Vertical air motion patterns, whether measured by radar, aircraft, or some other means, are usually not available. Radar reflectivity measurements, on the other hand, are commonly available to depict the structure of the precipitation field at high resolution $(\sim 1-2 \mathrm{~km})$ over large regions of the atmosphere. Therefore, practical methods for distinguishing regions of atmospheric convection from regions of stratiform air motions and precipitation growth use the reflectivity field alone. In this

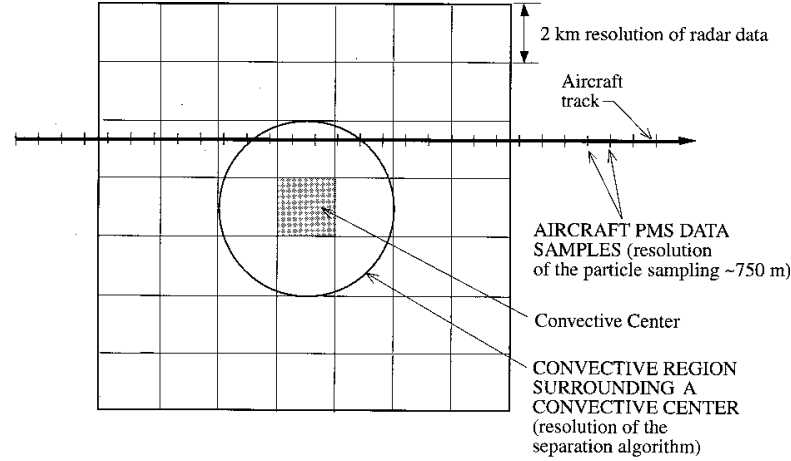

FIG. 2. Illustration showing a grid with radar reflectivity data classified into convective and stratiform regions. Particle-probe measurements (represented by tick marks along the flight track) obtained within convective regions according to the convective-stratiform map derived from radar data are classified as convective, and those obtained within stratiform regions are classified as stratiform. Particle-probe samples obtained within grid boxes classified as less than half convective (less than $2 \mathrm{~km}$ from convective grid boxes) were not put into either the convective or the stratiform category.

study, we employ an algorithm first developed for application to $4 \mathrm{~km} \times 4 \mathrm{~km}$ grids (Churchill and Houze 1984) and later refined for application to $2 \mathrm{~km} \times 2 \mathrm{~km}$ grids (Steiner et al. 1995). This method identifies regions of convection and declares the rest of the radar echo to be stratiform. We apply the method to the LF composite maps constructed from the P-3 lower-fuselage radar data. The $2 \mathrm{~km} \times 2 \mathrm{~km}$ grid of the LF composite (represented by the background grid in Fig. 2) closely approximates the basic horizontal resolution of the LF radar data as determined by the beamwidth at the maximum range of the reflectivity data. However, $2 \mathrm{~km}$ is not the basic resolution of our analysis. Rather, the smallest feature we delineate in the convective-stratiform separation is the convective region. The method of convective-stratiform separation uses the intensity and texture of the precipitation (as depicted by the 2-kmresolution data) to indicate the general regions in which air is overturning convectively, and where it is not. A convective region thus identified on radar represents a general region of active convective up- and downdrafts. Such a region is usually much larger than $2 \mathrm{~km} \times 2$ $\mathrm{km}$.

The method of Steiner et al. (1995) marches across the $2 \mathrm{~km} \times 2 \mathrm{~km}$ grid and looks at the value of the reflectivity at each data point. The method decides, for each point in the grid, whether that point is a convective center. The reflectivity value centered at that point must satisfy one of two criteria to qualify as being a convective center: either it must exceed some specified value of reflectivity (which is so high that the point must undeniably be in a region of convection) or it must be a local maximum of reflectivity that stands out from the background reflectivity in the surrounding region (defined as a circle $22 \mathrm{~km}$ in diameter) by a specified amount. The second criterion is necessary because there 
is a wide range of intermediate reflectivity values that can be in either convective or stratiform regions. In this study, we primarily use the second criterion since the aircraft often flew at altitudes such that the radar beam intersected the bright band, resulting in broad areas of high reflectivity in the LF composite that confounded the threshold intensity criterion. The peakedness criterion only requires knowledge of the relative values of reflectivity in a localized area over which the beamwidth does not vary greatly. In appendix B, we describe more specifically how we implement these criteria.

Once the technique declares a point to be a convective center by one of the above criteria, a circular region around that point is declared to be a convective region. This region is $2-10 \mathrm{~km}$ in diameter. The diameter of the convective region is a function of the mean background reflectivity in the region (22 $\mathrm{km}$ in diameter) surrounding the convective center. Steiner et al. (1995) determined the convective region size by examining the 3D structure of the echo to judge whether the echo surrounding a convective center was convective or stratiform. We followed a similar procedure in this paper (see appendix B for details). Although the diameter is sometimes as little as $2 \mathrm{~km}$, the bulk of convective regions surrounding convective centers are approximately 5-6 km in diameter. Moreover, several convective regions often overlap or touch, so that the size of the total convective region is usually much greater than a few kilometers in horizontal dimension.

\section{c. Categorizing precipitation types for the drop size data}

This study aims to determine whether the raindrop size distribution differs statistically according to whether the precipitation on radar is within a convective or stratiform region. As discussed above, the convective and stratiform regions are gross subdivisions of the radar echo, the smallest convective region being as little as approximately $2 \mathrm{~km}$ in diameter, but more typically greater than $5 \mathrm{~km}$ in diameter. The aircraft sampled the raindrop size distributions in 6-s time intervals, which correspond to a flight track length of about $0.75 \mathrm{~km}$, or a factor of approximately one-third the scale of the smallest convective region. Thus, the aircraft sampled the raindrop size distribution numerous times as it traversed a convective or stratiform region (the tic marks on the flight track in Fig. 2). Within convective and stratiform echo regions, there is variability of both air motions and microphysics, and no individual 6-s sample obtained by the aircraft is by itself representative of the convective or stratiform region as a whole. This study examines the statistics of the raindrop size distributions sampled in the relatively gross convective and stratiform regions identified by radar.

To determine the statistics of the raindrop size distributions sampled in convective and stratiform regions, we must determine when the Electra aircraft, which measured the drop size distributions, was flying through convective or stratiform precipitation. To make this determination, we appeal to a dataset that is independent of the drop size measurements-namely, the echo patterns detected by lower-fuselage radars on the two NOAA P-3 aircraft flying in coordination with the Electra. More specifically, we applied the convective-stratiform separation method described above and in appendix B to the P-3 LF composite radar echo maps (section 2) to delineate the boundaries of areas of convective and stratiform precipitation. We then used the NCAR/RDP (Research Data Program) Zebra software (Corbet et al. 1994) to plot the position of the NCAR Electra aircraft track relative to these boundaries by overlaying the Electra flight track on the P-3 convective-stratiform map. From these overlays, we determined the segments of the Electra flight track that were in convective and stratiform precipitation regions. This procedure allowed us to categorize each 6-s sample of the raindrop size distribution according to whether it was obtained within a convective or a stratiform region.

If the radar echo intensity at a $2 \mathrm{~km} \times 2 \mathrm{~km}$ grid element was less than $15 \mathrm{dBZ}$, it was classified as weak echo and not designated as either convective or stratiform. The value at a grid point was thus designated as convective, stratiform, weak echo, or no echo. The weak echo category was introduced since sea clutter (echo from the rough ocean surface) and weak echo were difficult to distinguish in the LF composites. The PMS data were collected only when the Electra aircraft was in precipitation. An additional category was used to indicate when the aircraft was within $2 \mathrm{~km}$ of the edge of a convective region. This precaution assured that the PMS data were categorized only when the Electra aircraft was clearly within a convective or stratiform region and reduces the sensitivity of the results to the specific tuning of the algorithm.

The division of the particle-image data into convective and stratiform subsamples is dependent on accurate locations of both the Electra flight track and P-3 LF radar data. Global Positioning System corrected data were used for both the P-3 and Electra positions. The error in the absolute locations of the P-3 and Electra aircraft is less than $500 \mathrm{~m}$ (Friehe et al. 1996; S. Burns 1996, personal communication; D. Friesen 1996, personal communication). Other uncertainties in the objective classification of the LF composites into convective and stratiform areas are related primarily to beam filling (Rosenfeld et al. 1992) and the classification of the transitional stage of embedded convection and heavy fallstreaks (section 4a and appendix B). As a matter of safety, the Electra aircraft did not penetrate the most intense convective cores. Therefore, very high convective rain rates are not represented in the particle-image dataset. The large number of samples and the operational ease in sampling a range of stratiform conditions provides relatively high confidence that the spectrum of stratiform conditions has been adequately sampled. Ad- 

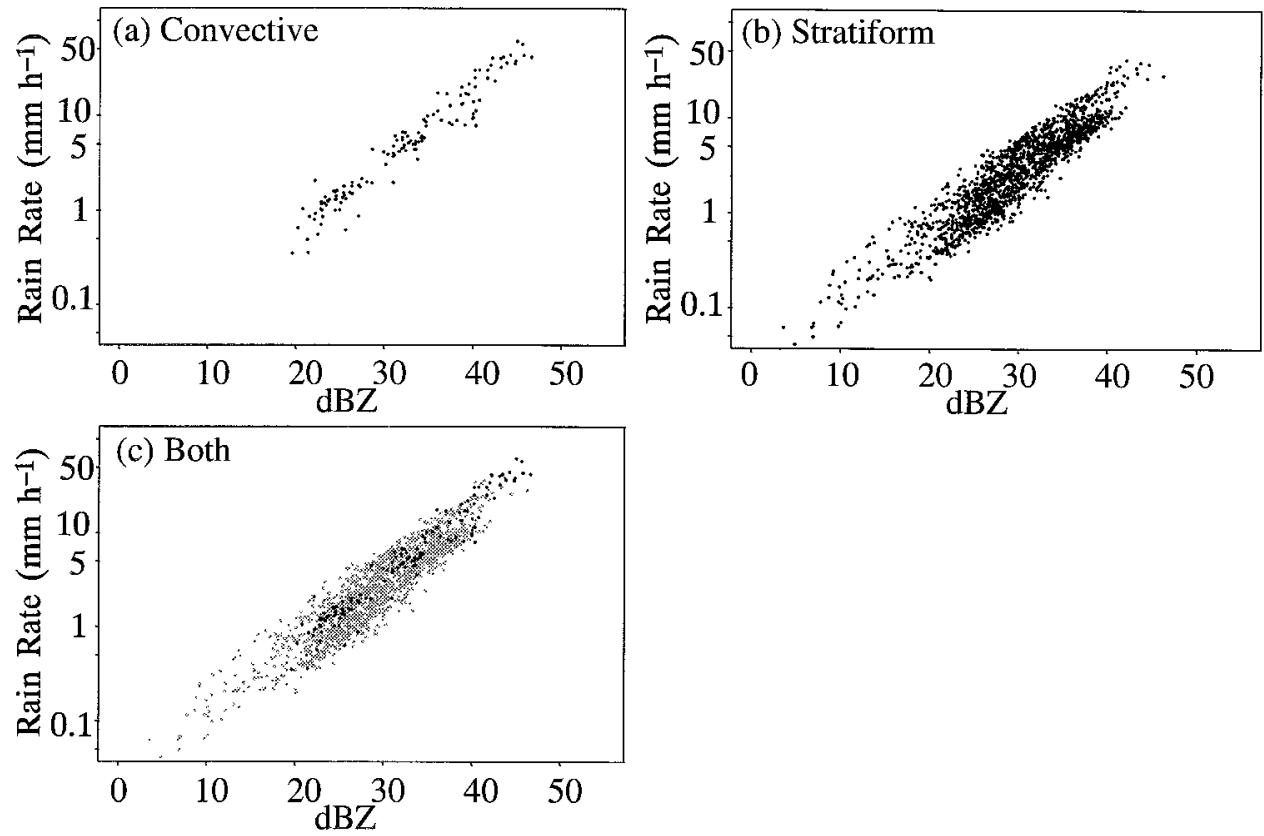

FIG. 3. Radar reflectivity and rain-rate data derived from Electra PMS data 6-s samples ( $\sim 750-\mathrm{m}$ spatial scale) classified using convective-stratiform maps computed from P-3 LF radar reflectivity composites. Samples are classified as (a) convective (133 6-s samples) and (b) stratiform (1793 6-s samples). (c) The two distributions overlaid, convective as black dots and stratiform as gray dots.

ditionally, the drop size distribution data are from the precipitation probe only. The PMS cloud probe data were not included, contributing up to a $5 \%$ error in overall rain rate statistics (R. Black 1995, personal communication). However, since rain rate and radar reflectivity are computed from the same drop size distribution, their relationship is accurate.

\section{Classified drop spectra}

For Electra missions occurring on 14 December 1992, 15 December 1992, 6 February 1993, 9 February 1993, and 10 February 1993, the set of 6-s samples falling within regions classified as convective or stratiform within the NOAA P-3 LF radar-derived convectivestratiform maps were extracted from the overall time

TABLE 3. Characteristics of the 136 out of 1793 stratiform drop spectra samples shown in Fig. 3, with rain rates greater than $10 \mathrm{~mm}$ $\mathrm{h}^{-1}$ at $3-\mathrm{km}$ altitude.

\begin{tabular}{|c|c|c|c|}
\hline $\begin{array}{c}\text { Distance from } \\
\text { convective } \\
\text { precipitation } \\
\text { region } \\
\text { boundary }\end{array}$ & Description & $\begin{array}{l}\text { Number } \\
\text { of } \\
\text { samples } \\
\text { with } \\
\text { rain } \\
\text { rates } \\
>10 \\
\mathrm{~mm} \mathrm{~h}^{-1}\end{array}$ & $\begin{array}{l}\text { Number } \\
\text { of } \\
\text { samples } \\
\text { with } \\
\text { rain } \\
\text { rates } \\
>20 \\
\mathrm{~mm} \mathrm{~h}^{-1}\end{array}$ \\
\hline $\begin{array}{l}3-10 \mathrm{~km} \\
>10 \mathrm{~km}\end{array}$ & $\begin{array}{l}\text { Transitional } \\
\text { Bright band with fallstreaks } \\
\text { Total }\end{array}$ & $\begin{array}{r}56 \\
80 \\
136\end{array}$ & $\begin{array}{r}16 \\
8 \\
24\end{array}$ \\
\hline
\end{tabular}

series of particle-image data. The sets of convective and stratiform points for the five missions are combined in Fig. 3. Although there are many more stratiform points than convective points, Fig. 3 shows that the distributions of convective and stratiform points overlap and do not form two distinct populations.

The population of drop spectra in convective regions encompasses rain rates from 0.3 to $62 \mathrm{~mm} \mathrm{~h}^{-1}$ and reflectivities from 19.5 to $46.5 \mathrm{dBZ}$. Within the stratiform population (Fig. 3b), 7.6\% of the samples have rain rates greater than $10 \mathrm{~mm} \mathrm{~h}^{-1}$ and $1.3 \%$ of the samples ${ }^{4}$ have rain rates greater than $20 \mathrm{~mm} \mathrm{~h}^{-1}$. Rain rates greater than $10 \mathrm{~mm} \mathrm{~h}^{-1}$ are unexpected given the conventional wisdom that rainfall-rate values higher than $10 \mathrm{~mm} \mathrm{~h}^{-1}$ are not characteristic of stratiform regions. What is the origin of these high-rain-rate stratiform drop spectra?

\section{a. Transitional regions}

Forty-one percent of the stratiform region rain-rate samples greater than $10 \mathrm{~mm} \mathrm{~h}^{-1}$ were obtained when the aircraft was $3-10 \mathrm{~km}$ from a convective region boundary (Table 3). The available ELDORA tail radar data indicate that these samples were obtained in regions where the reflectivity field was in transition from the

\footnotetext{
${ }^{4}$ The majority of drop spectra samples obtained within stratiform regions with rain rates greater than $20 \mathrm{~mm} \mathrm{~h}^{-1}$ (16 out of 24) were obtained on the mission of 6 February 1993, which investigated a cyclone rainband.
} 


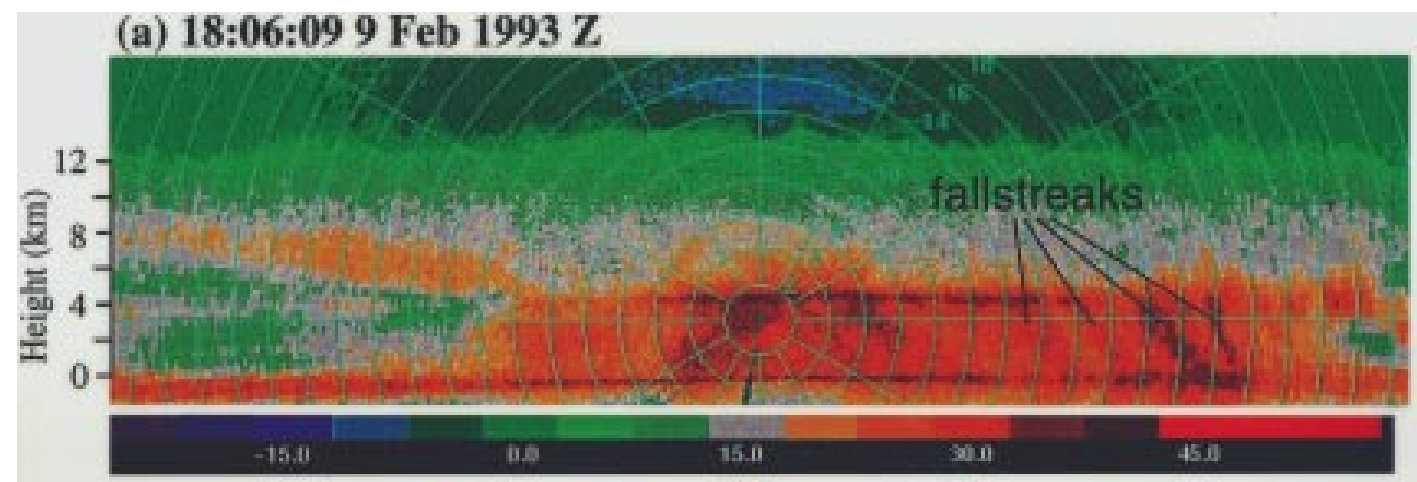

(b) 18:06:09 9 Feb $1993 \mathrm{~V}$

\section{$\mathrm{dBZ}$}

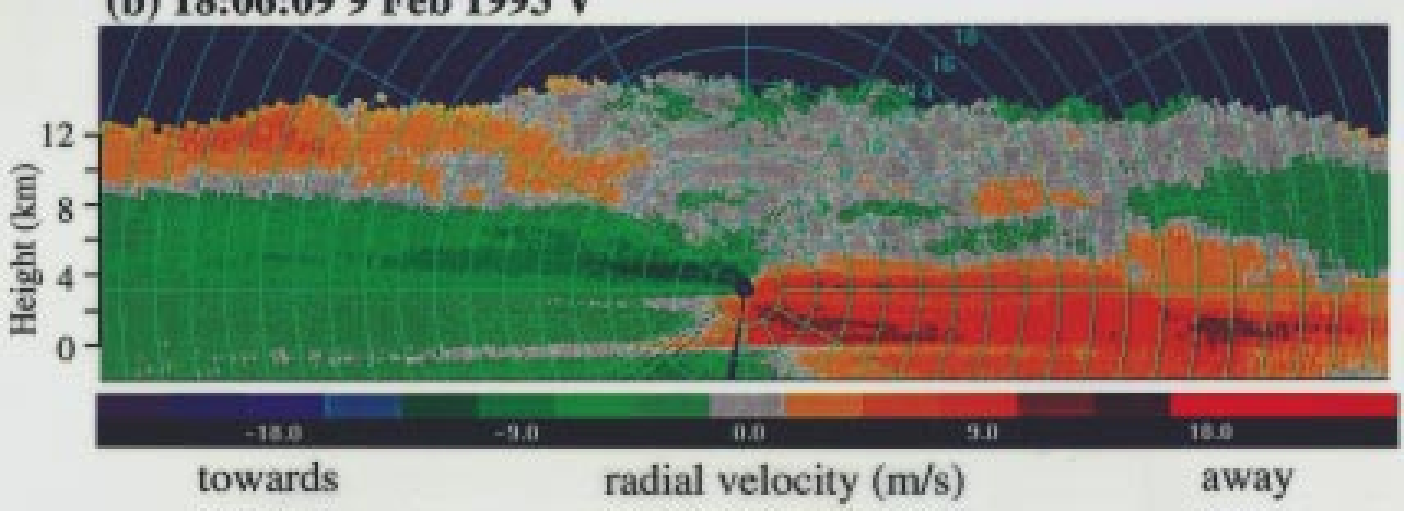

FIG. 4. Vertical structure $\left( \pm 20^{\circ}\right.$ from vertical) roughly perpendicular to the aircraft track from ELDORA tail radar onboard the NCAR Electra. (a) Radar reflectivity at 1806:09 UTC 9 February 1993 and the (b) corresponding unfolded radial velocity with aircraft motion removed. (c) Radar reflectivity at 1923:49 UTC 9 February 1993 and the (d) corresponding unfolded radial velocity with aircraft motion removed. Range rings at 2-km intervals are centered on the position of the Electra aircraft, which is at approximately $3-\mathrm{km}$ altitude.

vertically oriented maxima, characteristic of convective precipitation, to the layered appearance of stratiform precipitation (section 3a). We could have adjusted the objective convective-stratiform separation algorithm to force these points into the convective category. However, statistical analysis of simultaneous high-resolution measurements of radar reflectivity and dual-Doppler vertical velocity has shown that the most commonly occurring vertical air motions within transitional regions are weak and stratiform in character before the reflectivity pattern appears fully uniform in vertical cross sections (Yuter and Houze 1995b). Since the vertical velocity characteristics of transitional regions appear to be primarily stratiform, we suggest that their classification as stratiform in the objective convective-stratiform separation algorithm is reasonable. Therefore, occasional high-rain-rate samples obtained within these transitional regions will be included in the stratiform drop spectra population.

\section{b. Fallstreaks}

The majority $(59 \%)$ of the stratiform drop spectra with rain rates greater than $10 \mathrm{~mm} \mathrm{~h}^{-1}$ were obtained more than $10 \mathrm{~km}$ from a convective region boundary (Table 3). When available, the corresponding ELDORA tail radar data exhibited a radar bright band, the classic signature of stratiform precipitation. An example of such a situation is illustrated by Figs. 4a, 4b, 5a, and 6. The Electra aircraft was flying within a stratiform region approximately $30 \mathrm{~km}$ from any convective region (Fig. 5a). The ELDORA tail radar data at 1806:09 UTC 9 February 1993 contain a strong bright band of 30- to $45-\mathrm{dBZ}$ intensity and weak reflectivities above the $0^{\circ} \mathrm{C}$ level ( $\sim 4 \mathrm{~km})$, extending to an altitude of $13 \mathrm{~km}$ (Fig. 4a). Since the tail radar antenna sweeps out a cone oriented about $20^{\circ}$ perpendicular to the aircraft heading, the radial velocities directly above and below the aircraft contain components of both the vertical and horizontal velocity vectors. Fallstreaks in the reflectivity pattern are the elongated maxima of reflectivity extending downward from the bright band (Fig. 4a). Fallstreaks are commonly seen in stratiform precipitation and are either the remnants of deep convective cells or the result of overturning induced by cooling in the melting layer. The radial velocity data in Fig. $4 \mathrm{~b}$ indicate that the winds are laminar, blowing from left to right below an altitude 
(c) 19:23:49 9 Feb $1993 \mathrm{Z}$

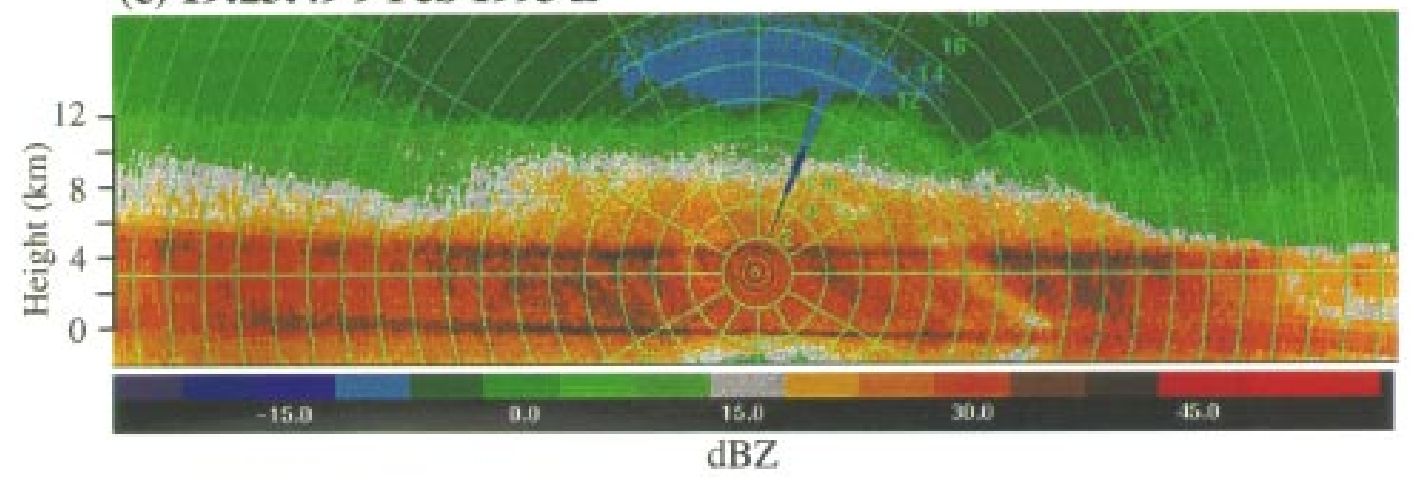

(d) 19:23:49 9 Feb $1993 \mathrm{~V}$

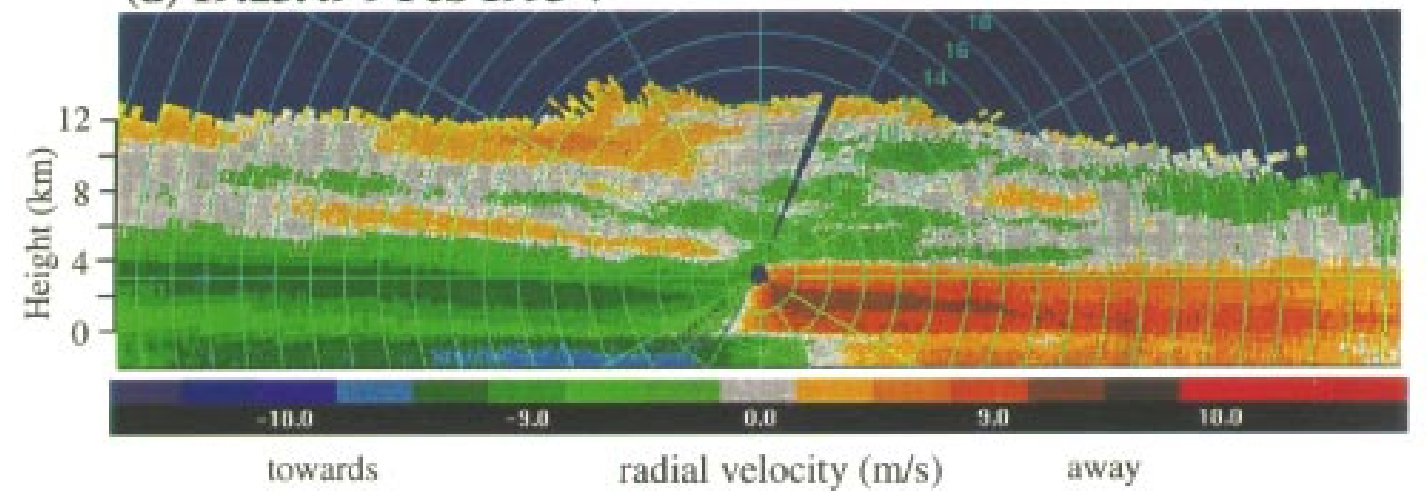

FIG. 4. (Continued)

of $9 \mathrm{~km}$. The shear of the wind produces the bending of the fallstreaks in the reflectivity pattern.

Time series data of vertical velocity and PMS-derived rain rate and reflectivity collected at a flight level averaged $^{5}$ over three different time periods corresponding to three distances along the flight track $(6 \mathrm{~s}-0.75 \mathrm{~km}$, $18 \mathrm{~s}-2.25 \mathrm{~km}$, and $32 \mathrm{~s}-4.5 \mathrm{~km}$ ) provide additional information on the local setting in which the drop spectra were sampled. The flight track segment classified as stratiform (section 3c) corresponding to Figs. 4a,b is from 1802:44 to 1806:32 UTC. Along this segment of the Electra's track, the average rainfall rate is $9.1 \mathrm{~mm}$ $\mathrm{h}^{-1}$ and the reflectivity is $36.4 \mathrm{dBZ}$. The magnitude of the flight-level vertical velocity is near $0 \mathrm{~m} \mathrm{~s}^{-1}$, much less than the fallspeed of drops (section 3a). The sharp peak in rainfall rate at 1804:16 at $24.6 \mathrm{~mm} \mathrm{~h}^{-1}$ (solid line in Fig. 6a) is smoothed to a value of approximately $14 \mathrm{~mm} \mathrm{~h}^{-1}$ at a $2.25-\mathrm{km}$ spatial scale (dashed lines in Fig. 6a). The values of rainfall rate, reflectivity, and vertical velocity exhibit a high spatial frequency variability that is captured by the $750-\mathrm{m}$ data (solid lines) but is considerably reduced at $2.25-\mathrm{km}$ (short dashed lines) and 4.5-km (long dashed lines) spatial scales.

\footnotetext{
${ }^{5}$ Radar reflectivity data $\left(\mathrm{mm}^{6} \mathrm{~m}^{-3}\right)$ are averaged and then converted to $\mathrm{dBZ}$.
}

Time series data such as in Fig. 6 indicate that high rain rates $\left(\gg 10 \mathrm{~mm} \mathrm{~h}^{-1}\right)$ in stratiform rain occur as sharp peaks in the 6-s $(750 \mathrm{~m})$ data but are usually smoothed out when the data are averaged to $2.25-\mathrm{km}$ (similar to the scale of the LF composites) and $4.5-\mathrm{km}$ spatial scales.

Later during the same flight (1923:49 UTC 9 February 1993), the stratiform region was more mature and the aircraft was farther away from active convective regions (Fig. 5b). Reflectivities in the ELDORA tail radar data (Fig. 4c) had higher values above the bright band, although the echo top was slightly lower than at 1806:09 (Fig. 4a). Fallstreaks were again evident, bending from left to right with the wind shear below the bright band (Figs. 4c,d). The time series for 1921:111925:31 UTC (Fig. 7) has a lower average rain rate (3.7 $\mathrm{mm} \mathrm{h}^{-1}$ ) and average reflectivity $(33.9 \mathrm{dBZ})$. The high spatial frequency variability within the $R, Z$, and $w$ data is present but is of smaller amplitude than during the 1802:44-1806:32 UTC time series.

The features of high spatial variability seen in the time series (Figs. 6 and 7) correspond to fallstreaks seen on airborne tail radar (Fig. 4). Within the more intense fallstreaks, reflectivity values were as high as $40 \mathrm{dBZ}$ (rain rates up to approximately $25 \mathrm{~mm} \mathrm{~h}^{-1}$ ). However, fallstreaks were not always associated with high rain rates (Figs. 4, 6, and 7). The likelihood that intersection 
(a) 18079 Feb 1993

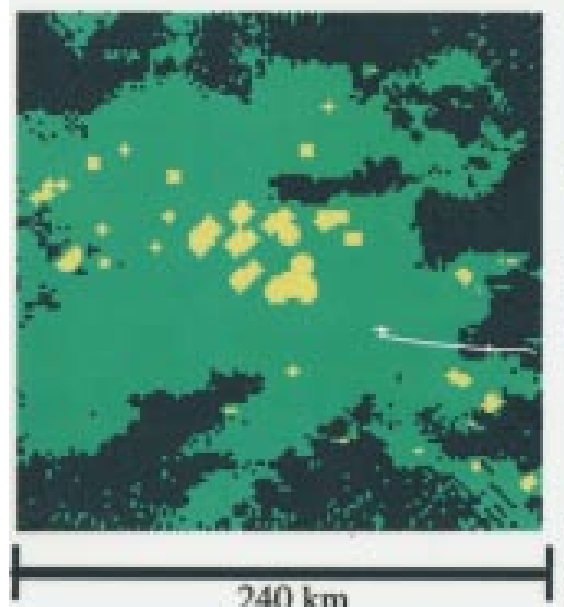

$240 \mathrm{~km}$ (b) 19249 Feb 1993

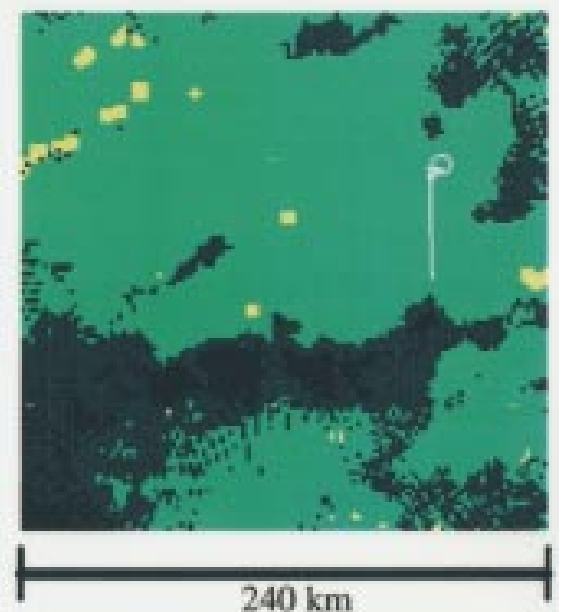

\section{Convective}

\section{Stratiform}

Weak Echo

No Echo

FIG. 5. Horizontal maps of $240 \mathrm{~km} \times 240 \mathrm{~km}$ area at $2 \mathrm{~km} \times 2 \mathrm{~km}$ resolution derived from NOAA P-3 LF composites classified as convective, stratiform, weak echo $(<15 \mathrm{dBZ})$, and no echo. Aircraft tracks are white and $10 \mathrm{~min}$ in length. (a) Convective-stratiform map with the position of the aircraft at 1807 UTC 9 February 1993 indicated by the plane symbol at left end of track. (b) Convective-stratiform map with the position of the aircraft at 1924 UTC 9 February 1993 indicated by the plane symbol at the end of the track.

of a fallstreak at $3 \mathrm{~km}$ would yield drop spectra with high rain rates is increased when the fallstreak reflectivity is high and when the stratiform region is comparatively young (e.g., the region has more recently transitioned to stratiform). The radar and time series data indicate that the fallstreaks are between about 0.1 and $2 \mathrm{~km}$ in diameter. Thus, only data sampled at spatial resolutions finer than the fallstreak diameters can resolve the high peak rain rates associated with intense fallstreaks. At coarser resolution, these high-rain-rate peaks will be smoothed out. Additionally, the rain rate at an altitude of $3 \mathrm{~km}$ is not the same as the surface rain rate.

During TOGA COARE, fallstreaks were commonly observed within stratiform regions by both the NCAR Electra and NOAA P-3 tail radars and by the National Aeronautics and Space Administration (NASA) DC-8 ARMAR (airborne rain-mapping radar) downwardlooking radar (Durden et al. 1994). The fallstreaks are visible in the airborne tail radar data since the airborne tail radar beam sweeps around an axis parallel to the earth's surface and thus obtains very fine resolution data in a continuously updated conical vertical cross section (section 2b). The shipborne radars used in TOGA COARE usually scanned around an axis perpendicular to the earth's surface and seldom obtained high-resolution vertical cross sections. The smoothing out of the fallstreak peaks at 2.25- and 4.5-km resolution (Figs. 6 and 7) indicates that individual fallstreaks within stratiform regions are usually not resolved at the scale of the interpolated LF composites and NASA TOGA COARE reflectivity maps $(2 \mathrm{~km} \times 2 \mathrm{~km}$; Kucera et al. 1995).

Since fallstreaks bend with the low-level wind shear and do not usually extend to the surface, there is also variability in reflectivity within vertical columns (Fig. 4). Thus, although relatively uniform in comparison to convective regions, stratiform regions contain discon- 

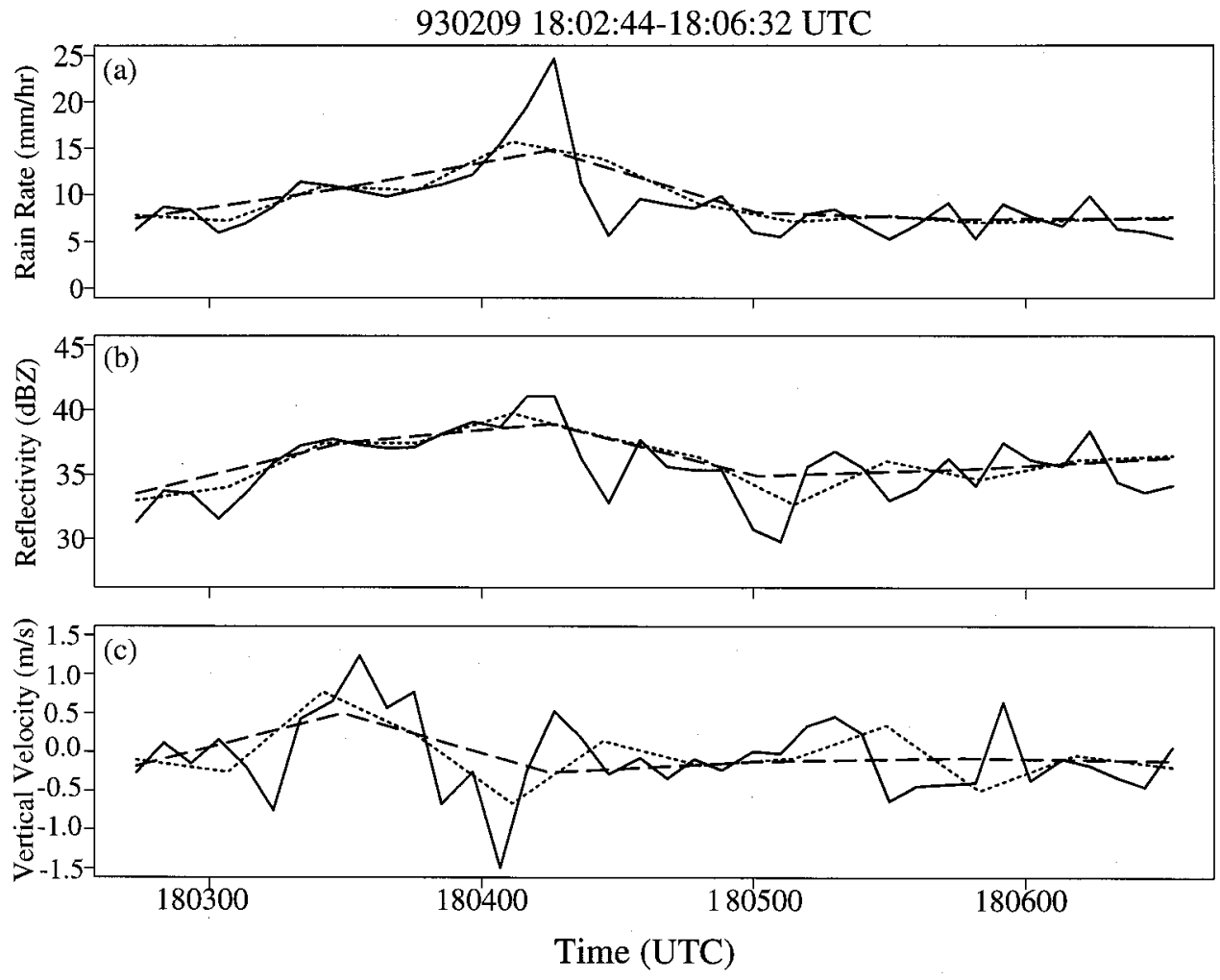

FIG. 6. Comparison of Electra flight-level (a) rain rate, (b) reflectivity, and (c) vertical velocity at three spatial scales. Flight-track segment is from 1802:44 to 1806:32 UTC 9 February 1993, corresponding to stratiform regions in Figs. 4a,b and 5a. In each plot, the samples are averaged over $6 \mathrm{~s}(\sim 750 \mathrm{~m})$ - solid line, $18 \mathrm{~s}(\sim 2.25 \mathrm{~km})$ - short-dashed line, and $32 \mathrm{~s}(\sim 4.5 \mathrm{~km})$-long-dashed line.

tinuities in drop spectra and associated microphysical processes at spatial scales of hundreds of meters.

Fallstreaks $0.1-2 \mathrm{~km}$ in horizontal scale have been observed since the earliest radar observations of stratiform precipitation (Battan 1973). As noted above, there are two main hypotheses to explain the origin of fallstreaks. The first is that they are remnants of convective cells. Yuter and Houze (1995c) referred to the ensemble of hydrometeor trajectories associated with a buoyant updraft element as a "particle fountain." In the convective stage of a storm, the buoyant parcels carry ice particles to the middle and upper levels of the storm and spread them laterally before they fall, just as jets of water in a fountain shoot up and spread out before falling to the ground in a gravitationally sorted pattern. As a convective region dies out and the precipitation takes on a stratiform character, the ice particles left aloft by the old spreading buoyant elements (the upper portion of old particle fountains) are local maxima in ice particle concentrations. These concentrated particles gradually fall out through the region of weak stratiform ascent. The concentrated particles likely aggregate, melt into large drops, and manifest themselves as fallstreaks below the $0^{\circ} \mathrm{C}$ level. The other hypothesis holds that fallstreaks are produced within the melting layer itself. Convective destabilization produced by melting leads to overturning within the melting layer and creates an environment favorable for liquid water collection. These local regions of favored liquid water collection within the melting layer produce larger drops, which upon falling through the layer become fallstreaks. The datasets in this study cannot address the validity of these theories. We speculate that some combination of these processes are at work in the production of fallstreaks.

\section{c. Large- and small-drop spectra within stratiform regions}

At a given rain rate (for rates in the range $1-10 \mathrm{~mm}$ $\mathrm{h}^{-1}$ ), the points in Fig. 3 are spread over about $9 \mathrm{~dB}$. Since each point is derived from a separate measurement of the drop size distribution, this 9-dB spread indicates the presence of a wide range of drop spectra characteristics, which encompass both large- and small-drop spectra. When the data from the two flight segments represented in Figs. 6 and 7 are highlighted in the $Z-R$ plot of the stratiform population (Fig. 8), it is clear that a broad range of drop spectra can occur within unambiguously stratiform conditions. Profiler observations from Darwin, Australia, have also indicated a wide range of drop spectra median volume diameters within tropical stratiform regions (Fig. 9 in May and Rajopadhyaya 

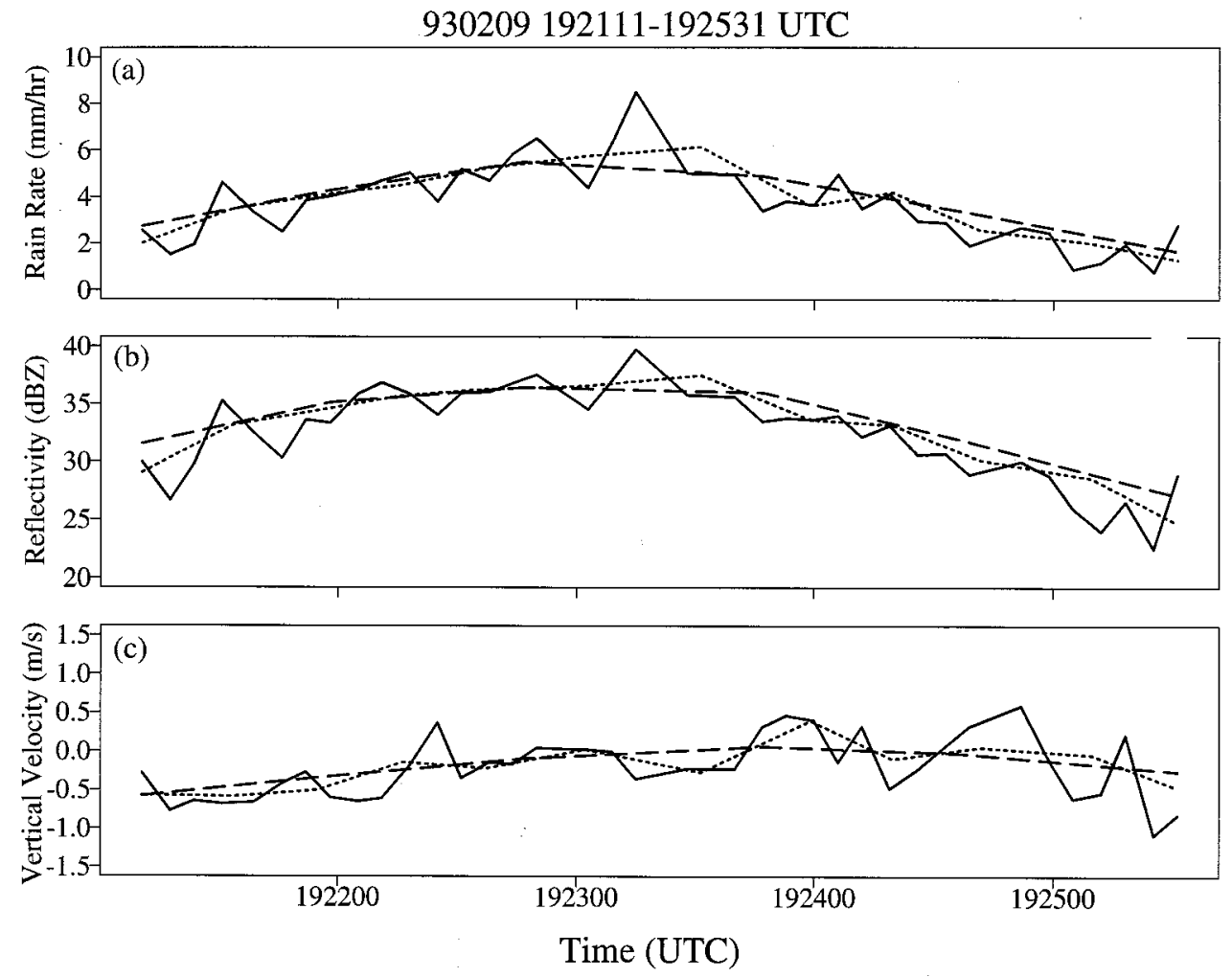

FIG. 7. Same as Fig. 6 except flight track segment is from 1921:11 to 1925:31 UTC 9 February 1993, corresponding to the stratiform region in Figs. $4 \mathrm{c}, \mathrm{d}$ and $5 \mathrm{~b}$.

1996). Waldvogel (1974) noted that a change from smallto large-drop spectra, manifested as an increase in the overall magnitude of reflectivity, could occur where a uniform bright band was present within extratropical storms (see his Fig. 2). Huggel et al. (1996) have noted both small- and large-drop spectra within precipitation regions exhibiting a distinct bright band as well.

Stratiform precipitation occurs when the vertical velocity of the air in which ice particles grow and fall out is generally small compared to the fall speed of snow. In such situations, the larger snow crystals often aggre-

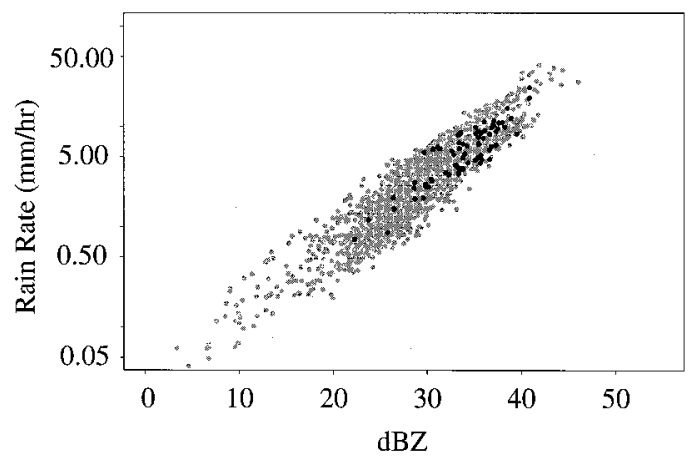

FIG. 8. Radar reflectivity versus rain rate for stratiform samples (same as Fig. 3b), with points from the two time series in Figs. 6 and 7 highlighted. gate and thus discontinuously form much larger particles. This process adds nothing to the mass of the precipitation, but when these large ice aggregates melt, they form large raindrops. Portions of stratiform regions in which aggregation is active thus produce rain with large-drop spectra (Waldvogel 1974; Braun and Houze 1994). Other portions of stratiform regions, where aggregation is not so active, or where only smaller particles are aggregating, produce much smaller raindrops when they melt.

Whether or not aggregation is active depends on a subtle mixture of conditions. Production of large aggregates is enhanced when the sizes of the constituent ice crystals are larger and the crystals are branched (Hobbs et al. 1974). Rimed snow crystals are less likely to aggregate and are associated with small-drop spectra (Waldvogel et al. 1995). Low ice particle concentrations less than $1 \mathrm{~L}^{-1}$ also tend not to form aggregates (A. Rangno 1996, personal communication). Weak ascent of the air through which a group of ice crystals is falling appears to enhance the formation of aggregates (Braun and Houze 1994). For our present concern, we note that because the circumstances under which aggregation of large particles is active are sensitive to a variety of conditions, it is reasonable to expect a dichotomy of drop size spectra in stratiform rain: large-drop spectra when large aggregates have been forming and melting, and small-drop spectra when they have not. This rea- 


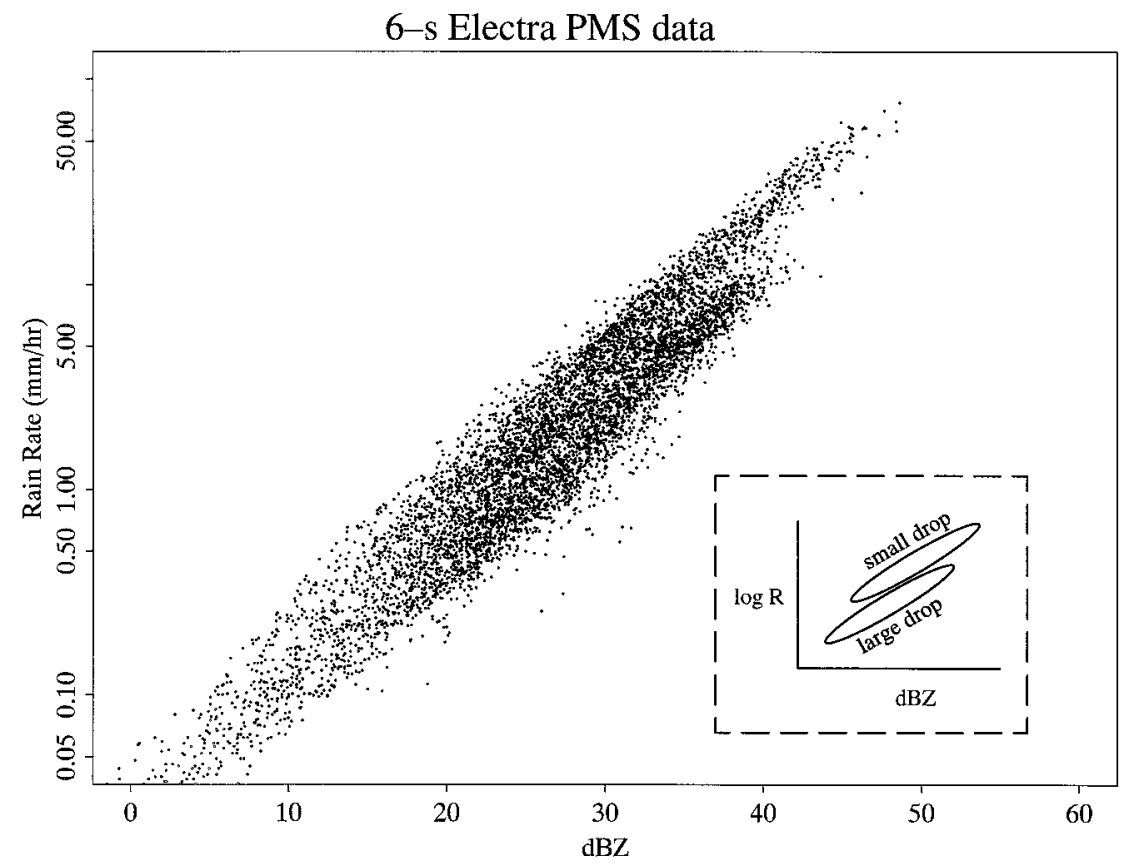

FIG. 9. Radar reflectivity data vs rain rate derived from Electra PMS data for all samples meeting conditions described in section $2 \mathrm{a}$ (7022 6-s samples). Inset is a sketch of relative positions for populations of large- and small-drop spectra within the figure.

soning is consistent with Fig. 3, which shows that the stratiform precipitation distinguishable in radar data encompasses both small- and large-drop spectra. Moreover, the occurrence of large aggregates can be sporadic. Houze and Churchill (1987) found that regions of large aggregates appeared suddenly and intermittently along the aircraft flight path within oceanic tropical stratiform precipitation. Figure 3 shows that for heavier stratiform rain rates, both small-drop and large-drop spectra exist, while weaker stratiform rain rates most often have a small-drop spectrum. Whenever ELDORA tail radar data were available, we verified that the high rain rates in the stratiform drop spectra population were obtained either in regions containing fallstreaks emanating from a well-defined bright band (section 4 b; e.g., Figs. 4 and 6 ), or in transitional regions in the vicinity of convective regions (section $4 \mathrm{a}$ ).

It is thus clear that the populations of small- and largedrop spectra do not correspond uniquely to convective and stratiform regions since stratiform precipitation itself contains a broad range of drop spectra. It follows that a convective-stratiform separation method that uses drop size distribution characteristics such as mean volume diameter as the separation criterion (e.g., Tokay and Short 1996) will not be effective.

\section{5. $Z-R$ relations}

Since the sets of $Z-R$ points for convective and stratiform regions do not form statistically distinct populations (Fig. 3), it is reasonable to derive a single $Z-R$ relationship that applies to all the Electra PMS data collected between 2.7 and $3.3 \mathrm{~km}$ (Table 1). When we plot all the 6-s sample values from the PMS probe in the same $Z-R$ graph (Fig. 9), the points from large- and small-drop spectra samples are evident, as indicated in the inset. A higher $Z$ is associated with the same $R$ if the drop spectrum producing the reflectivity contains larger drops. When the PMS data are averaged to approximately a $2.25-\mathrm{km}$ spatial scale (18-s samples ${ }^{6}$ instead of 6-s samples), the two drop size populations remain evident (Fig. 10).

\section{a. Exponential and probability-matched fits}

The traditional method of combining a set of $Z-R$ points into a practicable function is to fit the points to a relation of the form $Z=a R^{b}$, where $a$ and $b$ are positive constants. Usually, $Z$ and $R$ are plotted on the log scale, and $a$ and $b$ are derived from the slope and intercept of a straight line fit to the $Z-R$ points. This procedure, however, is sensitive to the number of points in the sample (Smith et al. 1993) and to the time-space resolution of the samples of the drop size distribution on which each $(Z, R)$ is based. For the Electra data in this

\footnotetext{
${ }^{6}$ The $18 \mathrm{~s}$ of PMS data in the 18 -s samples were collected within less than 21 contiguous seconds of flight.
} 


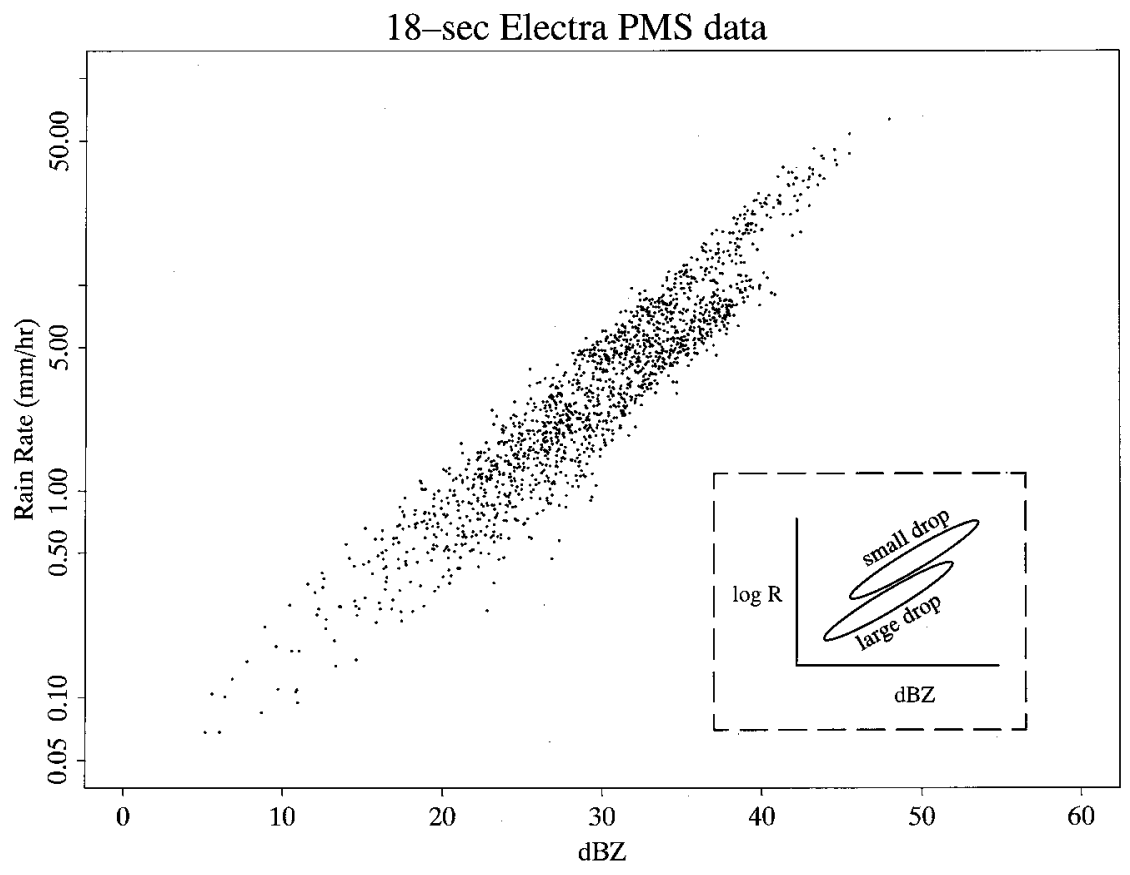

FIG. 10. Same as Fig. 9 except that PMS samples were averaged over $18 \mathrm{~s}(\sim 2.25-\mathrm{km}$ contiguous horizontal scale, 1632 samples).

study, the least squares median ${ }^{7}$ exponentially fitted $Z-$ $R$ relations are $Z=261 R^{1.45}$ for the 6-s samples and $Z$ $=137 R^{1.76}$ for the 18 -s samples. The $Z-R$ relations obtained by probability matching - that is, by matching the percentile values of $Z$ and $R$ (Calheiros and $\mathrm{Za}$ wadzki 1987; Rosenfeld et al. 1993; Houze 1993, chapter 4)-are nearly identical for the 6- and 18-s samples for rain rates greater than $1 \mathrm{~mm} \mathrm{~h}^{-1}$ (Fig. 11). The stability of the probability-matched relationship implies that the drop size data obtained on small time- and/or spatial scales are more likely applicable at the resolution of the radar measurements if the $Z-R$ relation is inferred from the data by probability matching than by an exponential fit. In the case of oceanic precipitation in COARE, we recommend using the probability-matched relation (Table 4). If an exponential-fit relation is used, one should use a relation appropriate to the scale of the radar data to which it is applied.

Since the Electra did not fly through intense convective cores, there are no data $49 \mathrm{dBZ}$ and greater upon which to base a probability-matched relationship. We assign reflectivity values greater than or equal to $49 \mathrm{dBZ}$ to $100 \mathrm{~mm} \mathrm{~h}^{-1}$, based on extending the trend in the data. Although very coarse, this approximation will have only a small effect on rainfall statistics since less than $1 \%$ of TOGA COARE ship radar reflectivity data exceed

\footnotetext{
${ }^{7}$ A least squares median fit is similar to a least squares fit but is less sensitive to outliers (more robust) than a least squares fit (Rousseuw and Leroy 1987).
}

$40 \mathrm{dBZ}$ (C. Leary and T. Doggett 1995, personal communication).

\section{b. Calculation of $Z-R$ relation using rain rates adjusted for vertical air motions}

We recomputed the drop size distribution rain rates by adjusting for the vertical motion of the air (Atlas et al. 1995). For this purpose, we used the average vertical velocity $\bar{w}\left(\mathrm{~cm} \mathrm{~s}^{-1}\right)$ measured by the aircraft at flight level during the same 6-s periods in which the drop size data were obtained. We used the formula

$$
R_{w}=6000 \pi \sum_{i=1}^{32} n_{i} D_{i}^{3}\left[V\left(D_{i}\right)-\bar{w}\right] .
$$

The probability-matched relation was then computed for the $Z-R_{w}$ points and is shown in Fig. 11. The use of $R_{w}$ versus $R$ makes an insignificant difference in the computed probability-matched relation for the entire dataset (Table 4). Indeed, in Fig. 11, the crosses of the $Z-R_{w}$ relation and the $X$ 's of the $Z-R$ relation are so close that most of the points appear as star symbols. The physical reason for closeness of the probability-matched relations is the weak correlation between reflectivity and vertical velocity in the Electra PMS dataset (Fig. 12). The vast majority of higher-reflectivity data are associated with vertical air motions near zero. Although the Electra sample is biased in favor of sampling within stratiform regions (section 3c), the weak association between high values of reflectivity and vertical velocity was also observed in a highly convective line of Florida 


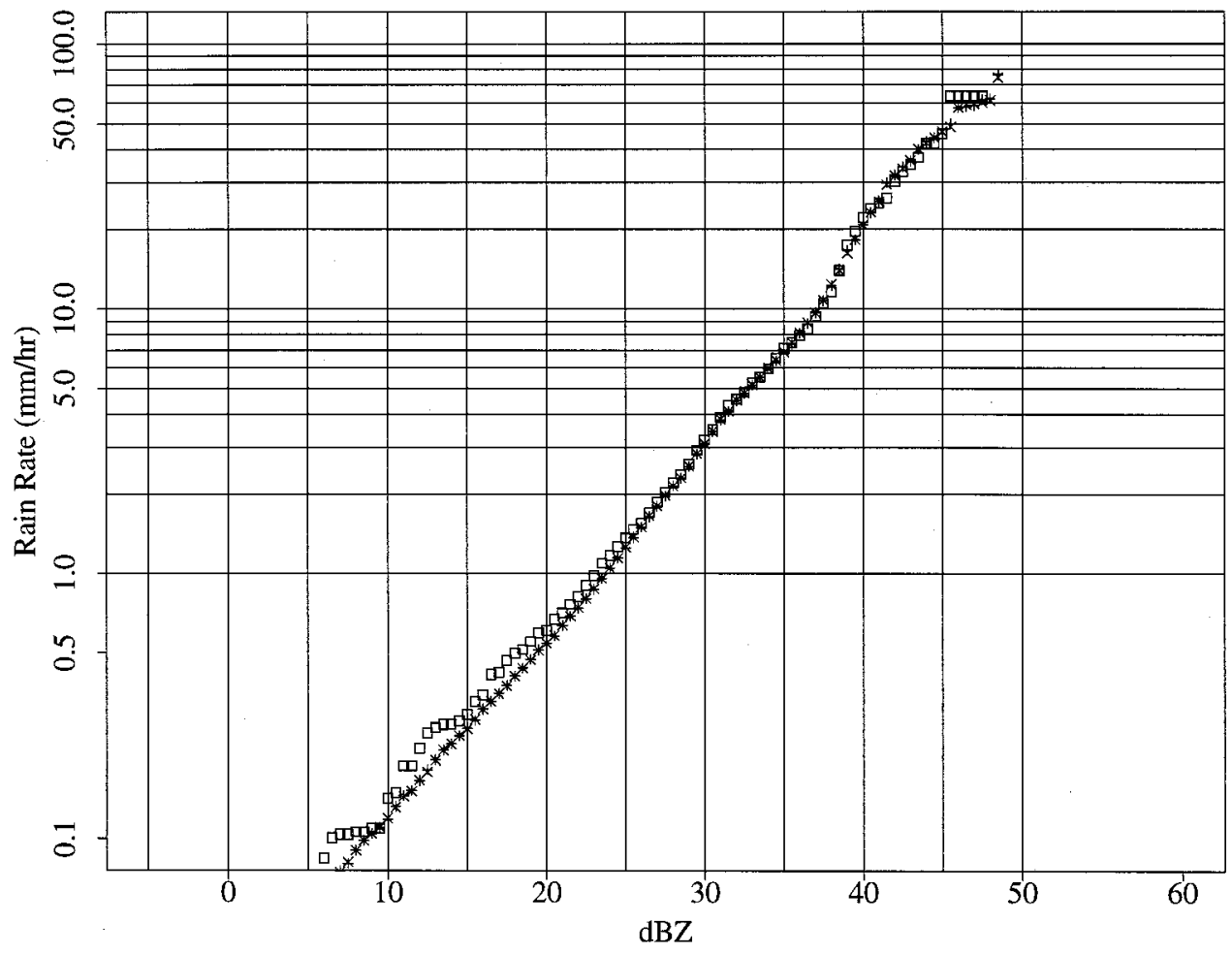

FIG. 11. Comparison of probability-matched relations; $\times$ 's-probability-matched $Z-R$ for 6-s samples, squares-probability-matched $Z-R$ for 18 -s samples, and crosses-probability-matched $Z-R_{w}$ (using vertical velocity adjusted rain rates) for 6-s samples. The probability-matched $Z-R$ and $Z-R_{w}$ relations for 6-s samples are nearly identical, so most of their respective data points appear as star symbols.

thunderstorms (Yuter and Houze 1995a). Thus, although outliers in the population can always be found where the computation of $R_{w}$ versus $R$ makes a large difference (Atlas et al. 1995), the statistics of the entire dataset do not yield a significant difference between probabilitymatched $Z-R$ relations computed with $R$ versus $R_{w}$.

\section{c. Comparison to other tropical $Z-R$ relations}

Figure 13 compares the $Z-R$ relations derived in this study to others that have been used for the TOGA COARE region. The TOGA COARE probability-matched relation is very similar to the Global Atmospheric Research Program (GARP) Atlantic Tropical Experiment (GATE) $Z-R$, with $Z=230 R^{1.25}$ (Hudlow 1979) for reflectivities greater than $20 \mathrm{dBZ}$. At reflectivities less than $20 \mathrm{dBZ}$, the corresponding rain rates are less than $0.5 \mathrm{~mm} \mathrm{~h}^{-1}$, and the slightly higher rain rates of the TOGA COARE relation compared to the GATE $Z-R$ will have a very minor effect on rainfall accumulations. However, the GATE $Z-R$ was obtained at the surface (on a ship), while the drop size samples from the Electra in TOGA COARE were obtained at approximately the $3-\mathrm{km}$ level. It remains to be determined whether the $Z$ $R$ relation at the ocean surface differs significantly from that at $3 \mathrm{~km}$. Figure 13 also indicates that application of our single $Z-R$ will increase rainfall in stratiform regions and decrease rainfall in convective regions compared to rainfall calculations based on the Tokay and Short (1996) Z-R's. These differences are potentially quantitatively important-Steiner and Houze (1997) show that using separate $Z-R$ relations for convective and stratiform regions can lead to estimates ranging from $30 \%$ to $80 \%$ for the fraction of total rain that is convective. The use of a single $Z-R$ relation reduces the range of estimates for the convective rain fraction to $40 \%-60 \%$.

\section{d. Considerations in the calculation of surface rainfall rates}

Most precipitation maps are in terms of surface rain rates. However, the scanning geometry of surface-based radars and the curvature of the earth conspire so that radar measurements cannot be made close to the surface at far ranges from the radar. For example, the altitude of the TOGA COARE ship radar reflectivity maps produced by NASA (Kucera et al. 1995) is $2 \mathrm{~km}$. Application of $Z-R$ relations derived from surface drop spectra (e.g., distrometer) measurements to radar data aloft can only be made when the nature of the precipitation in terms of $Z$ and $R$ is similar between the level of the measurements and the surface. A suggested procedure for producing surface rain maps from the shipborne ra- 
TABLE 4. Probability-matched $Z-R$ relation for Electra PMS data valid for 3-km altitude from an approximately $750-\mathrm{m}$ horizontal scale $(6 \mathrm{~s})$ data (section $5 \mathrm{a}$ ). Where the vertical velocity adjusted probability-matched $Z-R_{w}$ relation (section $5 \mathrm{~b}$ ) differs from the $Z-R$ by more than $0.01 \mathrm{~mm} \mathrm{~h}^{-1}$, the difference $R_{w}-R$ is shown in parentheses. Since the Electra did not penetrate intense convective cells, there are no data available at very high reflectivities. The last value in the table for radar reflectivity greater than or equal to $49 \mathrm{dBZ}$ is an approximation.

\begin{tabular}{|c|c|c|c|c|c|}
\hline $\begin{array}{l}\text { Radar } \\
\text { reflectivity } \\
(\mathrm{dBZ})\end{array}$ & $\begin{array}{l}\text { Rain rate } \\
\left(\mathrm{mm} \mathrm{h}^{-1}\right)\end{array}$ & $\begin{array}{l}\text { Radar } \\
\text { reflectivity } \\
(\mathrm{dBZ})\end{array}$ & $\begin{array}{l}\text { Rain rate } \\
\left(\mathrm{mm} \mathrm{h}^{-1}\right)\end{array}$ & $\begin{array}{l}\text { Radar } \\
\text { reflectivity } \\
(\mathrm{dBZ})\end{array}$ & $\begin{array}{l}\text { Rain rate } \\
\left(\mathrm{mm} \mathrm{h}^{-1}\right)\end{array}$ \\
\hline 0 & 0.02 & 16.5 & 0.33 & 33 & $5.16(+0.01)$ \\
\hline 0.5 & 0.02 & 17 & 0.35 & 33.5 & $5.52(+0.01)$ \\
\hline 1 & 0.03 & 17.5 & 0.38 & 34 & $5.94(+0.03)$ \\
\hline 1.5 & 0.03 & 18 & 0.41 & 34.5 & $6.37(+0.03)$ \\
\hline 2 & 0.03 & 18.5 & 0.44 & 35 & $6.87(+0.02)$ \\
\hline 2.5 & 0.04 & 19 & 0.47 & 35.5 & $7.4(+0.05)$ \\
\hline 3 & 0.04 & 19.5 & 0.51 & 36 & $8.11(+0.04)$ \\
\hline 3.5 & 0.04 & 20 & 0.54 & 36.5 & $8.81(+0.06)$ \\
\hline 4 & 0.04 & 20.5 & 0.58 & 37 & $9.71(-0.04)$ \\
\hline 4.5 & 0.05 & 21 & 0.64 & 37.5 & $10.74(+0.05)$ \\
\hline 5 & 0.05 & 21.5 & 0.69 & 38 & $12.25(+0.11)$ \\
\hline 5.5 & 0.06 & 22 & 0.74 & 38.5 & $14.13(-0.16)$ \\
\hline 6 & 0.06 & 22.5 & 0.8 & 39 & $16.63(-0.42)$ \\
\hline 6.5 & 0.07 & 23 & 0.87 & 39.5 & $18.2(+0.08)$ \\
\hline 7 & 0.08 & 23.5 & 0.96 & 40 & $20.8(-0.1)$ \\
\hline 7.5 & 0.08 & 24 & 1.05 & 40.5 & $23.07(+0.05)$ \\
\hline 8 & 0.09 & 24.5 & 1.15 & 41 & $25.47(-0.06)$ \\
\hline 8.5 & 0.1 & 25 & 1.25 & 41.5 & $29.92(-0.55)$ \\
\hline 9 & 0.1 & 25.5 & 1.37 & 42 & $31.99(-0.22)$ \\
\hline 9.5 & 0.11 & 26 & 1.5 & 42.5 & $34.36(-0.55)$ \\
\hline 10 & 0.12 & 26.5 & $1.65(+0.01)$ & 43 & $36.06(+0.25)$ \\
\hline 10.5 & 0.13 & 27 & 1.8 & 43.5 & $39.99(+0.09)$ \\
\hline 11 & 0.15 & 27.5 & $1.97(+0.01)$ & 44 & $42.76(-0.49)$ \\
\hline 11.5 & 0.15 & 28 & 2.15 & 44.5 & 44.26 \\
\hline 12 & 0.17 & 28.5 & $2.3(+0.01)$ & 45 & $47.86(-0.2)$ \\
\hline 12.5 & 0.18 & 29 & $2.55(+0.01)$ & 45.5 & $49.77(-1.13)$ \\
\hline 13 & 0.2 & 29.5 & $2.83(+0.01)$ & 46 & 57.41 \\
\hline 13.5 & 0.22 & 30 & 3.11 & 46.5 & $57.81(+1.21)$ \\
\hline 14 & 0.23 & 30.5 & 3.46 & 47 & $58.61(+0.82)$ \\
\hline 14.5 & 0.24 & 31 & $3.81(+0.03)$ & 47.5 & $61.66(-1.4)$ \\
\hline 15 & 0.26 & 31.5 & $4.1(+0.02)$ & 48 & $61.94(-0.85)$ \\
\hline 15.5 & 0.28 & 32 & $4.51(+0.02)$ & 48.5 & $76.38(-1.91)$ \\
\hline 16 & 0.31 & 32.5 & $4.8(+0.02)$ & $\geq 49$ & 100 \\
\hline
\end{tabular}

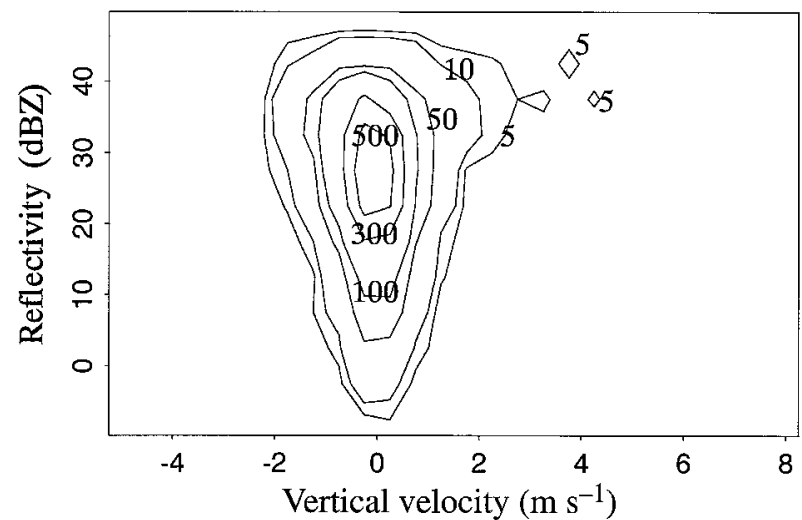

FIG. 12. Contoured scatterplot of reflectivity derived from Electra PMS 6-s data versus 6-s average flight-level vertical velocity. Histogram bin sizes are $0.5 \mathrm{~m} \mathrm{~s}^{-1}$ for vertical velocity and $5 \mathrm{~dB}$ for reflectivity. Contours are labeled according to number of points. dar reflectivity maps would be to apply a single probability-matched $Z-R$ relation derived from properly calibrated and sited distrometer measurements made over several months in the region of interest. Unfortunately, no such distrometer measurements were made during TOGA COARE. ${ }^{8}$ It should be a high priority of the tropical precipitation community to properly site a calibrated distrometer in the warm pool region to resolve this deficiency.

The observed PMS drop size distributions examined in this study are valid for a height of $3 \mathrm{~km}$. Therefore,

${ }^{8}$ The Kapingamarangi distrometer was not sited properly during TOGA COARE. The instrument was deployed near overhead obstacles and was not placed on a horizontally level surface (M. Susedik 1995, personal communication). 


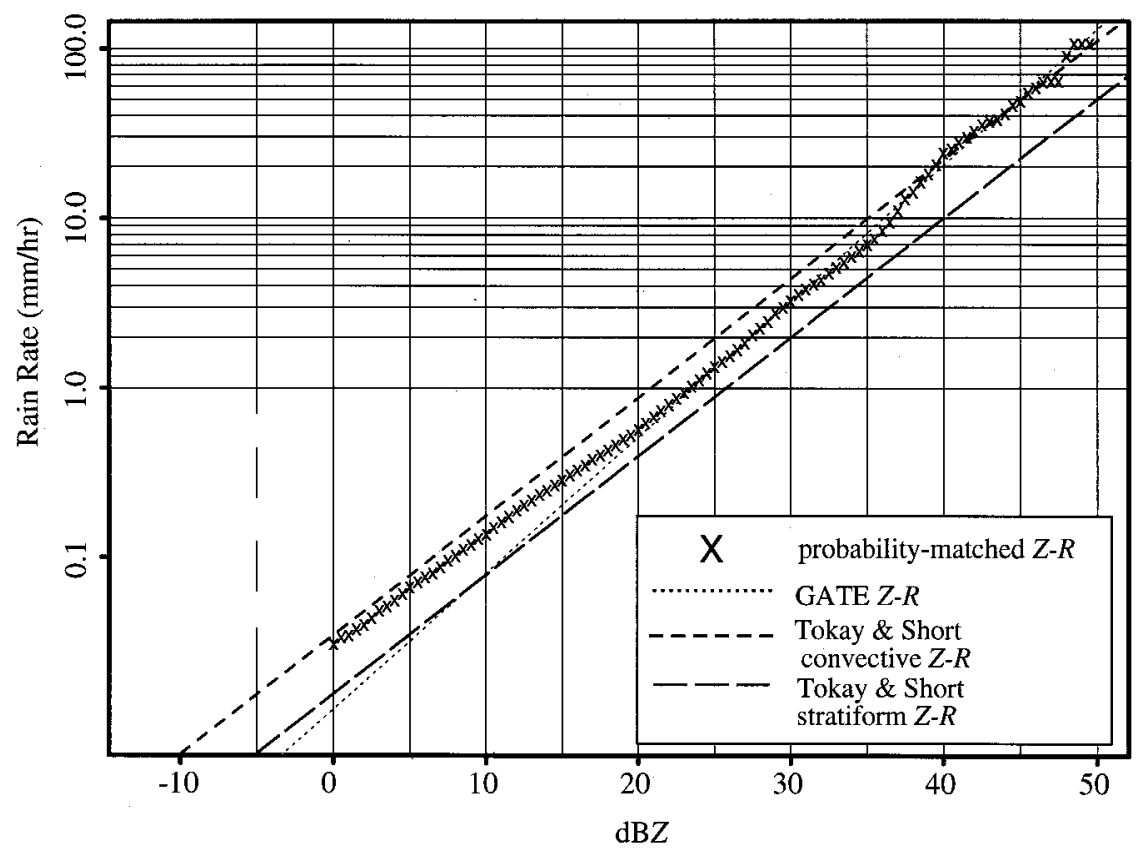

FIG. 13. Comparison of various $Z-R$ relations; $X$ 's-probability-matched $Z-R$ for 6-s samples from this study, dotted line-GATE $Z-R\left(Z=230 R^{1.25}\right)$, short-dashed line-Tokay and Short (1996) convective $Z-R\left(Z=139 R^{1.43}\right)$, and long-dashed line- Tokay and Short (1996) stratiform $Z-R\left(Z=367 R^{1.30}\right)$.

application of our $Z-R$ relation to the $2-\mathrm{km}$-altitude TOGA COARE shipborne radar data will not necessarily yield surface rain rates. The similarity of our $Z-$ $R$ relation to the GATE relation derived from surface distrometer data (Austin and Geotis 1979) suggests that the $Z-R$ relation does not change much between $3 \mathrm{~km}$ and the surface. However, possible changes in drop spectra and hence $Z-R$ from $3 \mathrm{~km}$ to the surface are extremely complex. The full set of processes affecting the drop distribution within a volume of air in the warm part of the cloud are air motions, nucleation from the vapor phase, vapor diffusion (condensation and evaporation), collection, drop breakup, and sedimentation or fallout [Houze 1993, chapter 3, Eq. (3.58)]. An additional complication is that fallstreaks intersected by the aircraft at $3 \mathrm{~km}$ do not usually extend to the surface.

Previous studies have shown that as distance below cloud base increases, the number of small droplets is progressively depleted and the relative number of large drops in the spectrum tends to increase (Rigby et al. 1954; Mason and Ramanadham 1954; List and Gillespie 1976; Hauser and Amayenc 1983; Levin et al. 1991; Hu and Srivastava 1995). However, the evolution of the drop spectrum with decreasing height does not change a small-drop spectrum into a large-drop spectrum or vice versa (May and Rajopadhyaya 1996). Thus, the finding that small- and large-drop spectra do not correspond to convective and stratiform precipitation would appear to be valid at the surface as well as aloft. Since net water is evaporated, the rain rate at the surface is less than the rain rate aloft (Best 1952; Fletcher 1966). While the nature of the changes occurring in the drop size distribution as rain falls from $3 \mathrm{~km}$ to the ocean surface can be described generally as above, an explicit microphysical model is needed to calculate it exactly. A detailed microphysical model calculation is beyond the scope of this study.

\section{Average conditional rain rates for convective and stratiform regions}

Average conditional rain rates-average rain rates for regions where it is raining-can be computed from the classified Electra PMS data for convective and stratiform regions (Table 5). The degree to which these averages represent climatological averages depends on how well the sampling mirrors the relative occurrence of the different rain rates over climatological space and timescales. Since partially filled sample volumes are excluded from the PMS dataset (section $2 \mathrm{a}$ ), the samples with rain rates less than $0.5 \mathrm{~mm} \mathrm{~h}^{-1}$ are those corresponding to continuous light rain, rather than intermittent moderate rain over the approximately $750 \mathrm{~m}$ of flight track. For stratiform regions, the large sample size over a wide variety of conditions provides confidence that the resulting average is reasonable. Since the previous studies (Table 5) to which ours is compared did not distinguish between weak echo and stratiform, we combine the stratiform and weak echo samples to obtain the average stratiform conditional rain rate. The Electra PMS conditional stratiform rain rate at $3-\mathrm{km}$ altitude is 1-2 $\mathrm{mm} \mathrm{h}^{-1}$ higher than those seen at the surface in 
TABLE 5. Conditional rain rates for convective and stratiform regions for present study and selected studies. To make the definition of stratiform conditional rain rate comparable to those in previous studies, stratiform and weak echo categories are combined to compute conditional stratiform rain rate from the present study. Rain rates are at the surface unless otherwise indicated.

\begin{tabular}{|c|c|c|c|c|}
\hline Study & Dataset & $\begin{array}{c}\text { Instrument } \\
\text { (horizontal } \\
\text { spatial scale) }\end{array}$ & $\begin{array}{l}\text { Conditional } \\
\text { convective cell } \\
\text { rain rate } \\
\left(\mathrm{mm} \mathrm{h}^{-1}\right)\end{array}$ & $\begin{array}{l}\text { Conditional } \\
\text { stratiform } \\
\text { rain rate } \\
\left(\mathrm{mm} \mathrm{h}^{-1}\right)\end{array}$ \\
\hline Present study & $\begin{array}{l}\text { TOGA COARE } \\
\text { Electra PMS }\end{array}$ & $\begin{array}{l}\text { Particle probe } \\
\quad(\sim 750 \mathrm{~m})\end{array}$ & $\geq 10.0$ at $3-\mathrm{km}$ altitude & 3.9 at $3-\mathrm{km}$ altitude \\
\hline $\begin{array}{l}\text { Leary } \\
\quad(1984)\end{array}$ & $\begin{array}{l}\text { GATE } \\
\quad 4-5 \text { September } 1974\end{array}$ & $\begin{array}{l}\text { Radar } \\
\quad(4 \mathrm{~km} \times 4 \mathrm{~km})\end{array}$ & 3 & 2.2 \\
\hline $\begin{array}{l}\text { Gamache and Houze } \\
\text { (1983) }\end{array}$ & $\begin{array}{l}\text { GATE } \\
12 \text { September } 1974\end{array}$ & $\begin{array}{l}\text { Radar } \\
\quad(4 \mathrm{~km} \times 4 \mathrm{~km})\end{array}$ & NA & 2.6 \\
\hline $\begin{array}{l}\text { Rappaport } \\
\text { (1982) }\end{array}$ & $\begin{array}{l}\text { GATE } \\
28 \text { June } 1974\end{array}$ & $\begin{array}{l}\text { Radar } \\
\quad(4 \mathrm{~km} \times 4 \mathrm{~km})\end{array}$ & NA & 3.3 \\
\hline $\begin{array}{l}\text { Braun and Houze } \\
\text { (1996) }\end{array}$ & $\begin{array}{c}\text { Kansas-Oklahoma } \\
\text { 10-11 June } 1985\end{array}$ & $\begin{array}{l}\text { Rain gauge } \\
\quad\left(\sim 100 \mathrm{~cm}^{2}\right)\end{array}$ & 20.9 & 2.9 \\
\hline
\end{tabular}

several storms during GATE and during a midlatitude squall line (Table 4). A difference of this magnitude in rain flux from $3 \mathrm{~km}$ to the surface is within the bounds of observed evaporative losses in tropical precipitation (May and Rajopadyaya 1996). Since intense convective regions were undersampled by the Electra, the average conditional rain rate for convective regions is a lower bound.

\section{Conclusions}

The large sample of drop size distributions represented in Fig. 9 confirms earlier studies (e.g., Short et al. 1990) in showing the presence of both large- and small-drop populations in tropical precipitation. However, when these samples, obtained in TOGA COARE by a particle-image probe along the approximately 750-m segments of flight track of the NCAR Electra aircraft, are classified according to whether they were obtained within areas of convective or stratiform precipitation as seen by the lower-fuselage radar on the NOAA P-3 aircraft, the populations of $Z-R$ points overlap (Fig. 3). Thus, we find that the separation of precipitation into convective and stratiform regions does not distinguish between small- and large-drop spectra.

The results in Figs. 3 and 8 show, moreover, that stratiform regions contain a wide distribution of drop spectra (approximately a 9-dB variation for a given rain rate), encompassing both large- and small-drop spectra. The small-drop spectra in stratiform regions arise from the melting of small ice particles. Flight-level data and high-resolution cross sections from the tail radar reveal that on scales of $0.1-2 \mathrm{~km}$, the stratiform region is highly variable microphysically and can contain local peaks of up to approximately $40 \mathrm{dBZ}$ in reflectivity and 25 $\mathrm{mm} \mathrm{h}^{-1}$ in rain rate. The large-drop spectra, higher rain rates, and higher reflectivities within stratiform regions are primarily associated with fallstreaks, which are likely the microphysical remnants of deep convection and/or convective overturning in the melting layer.

The broad distribution of rain rates and reflectivities within stratiform regions (Figs. 3 and 8) implies that regions containing small- or large-drop spectra do not have a unique signature in radar reflectivity or rainfall rate and that they can currently only be identified with direct measurements of the drop size distribution. Further, the microphysical properties of the stratiform precipitation are best characterized by the ensemble of drop spectra sampled within stratiform regions, rather than by any individual measurement of a small spatial-scale drop spectrum, which may not be representative of the stratiform region as a whole.

The ensemble of $Z-R$ values appears to be somewhat bimodal in character, corresponding to populations of large- and small-drop spectra (Fig. 9). However, there is as yet no apparent way to distinguish from radar reflectivity patterns alone which areas are characterized by these large- versus small-drop spectra. We have seen that for a given rain rate both large- and small-drop spectra can occur in stratiform precipitation (Fig. 3), so that a convective-stratiform separation algorithm does not make the distinction. Therefore, in the absence of a better alternative, we derived a single $Z-R$ relation, which fits the entire sample of 6-s drop size spectra (Table 3). It is valid for 3-km altitude, is derived by probability matching and, as compared to exponentially fitted $Z-R$ 's, is relatively insensitive to spatial averaging of the PMS measurements. The probability-matched $Z-$ $R_{w}$ relation recalculated using rain rates adjusted for vertical velocity (Atlas et al. 1995) is almost identical to the one calculated assuming that the drops are falling in stagnant air (Fig. 11 and Table 4). Our $Z-R$ relationship for $3 \mathrm{~km}$ is very similar to the GATE $Z-R$ for the surface (Hudlow 1979). Although it is an approximation, a single $Z-R$ relationship should produce less error than techniques that assume that convective and stratiform regions correspond to small- and large-drop spectra. A practical advantage is that a single $Z-R$ is much easier to apply since the radar data do not need to be subdivided into convective and stratiform regions in order to obtain rain rates.

The average conditional stratiform rain rate at $3-\mathrm{km}$ 
altitude and $750-\mathrm{m}$ scale is approximately $3.9 \mathrm{~mm} \mathrm{~h}^{-1}$, which is $1-2 \mathrm{~mm} \mathrm{~h}^{-1}$ higher than reported GATE stratiform rain rates at the surface (Table 4). This difference in precipitable water mass with altitude is consistent with the loss of water volume from evaporation observed in tropical precipitation (May and Rajopadhyaya 1996). The average conditional convective rain rate at $3-\mathrm{km}$ altitude is at least $10 \mathrm{~mm} \mathrm{~h}^{-1}$. This value is a lower bound since the Electra did not attempt to sample the most intense convective cells.

A method to distinguish regions containing small- and large-drop spectra from instantaneous radar data is needed before application of multiple $Z-R$ relations can be justified. Verification of such classifications will require independent drop size distribution measurements and large sample sizes. Differential reflectivity, a parameter available from multiple-polarization radars, may be useful in distinguishing regions of small-drop versus largedrop spectra.

Acknowledgments. Greatly appreciated are the help, advice, and comments of Marcia Baker, Darrel Baumgardner, Robert Black, Sean Burns, Shuyi Chen, Dick Friesen, Peter Hildebrand, David Kingsmill, Colleen Leary, Art Rangno, David Short, Matthias Steiner, and Christopher Williams. Special thanks go to Pauline Austin, Scott Braun, and Ed Zipser for their detailed comments on the manuscript. Candace Gudmundson edited the manuscript, and Kay Dewar prepared some of the figures. Gary Huitsing, Shannon O'Donnell, and Catherine Spooner assisted in the data processing. Datasets were provided by the National Oceanographic and Atmospheric Administration and the Atmospheric Technology Division of the National Center for Atmospheric Research. This research was supported by NASA/Earth Observing System Global Change Fellowship NGT30100, ONR Grant N00014-93-1-1271, NOAA Cooperative Agreements NA37RJ0198 and NA67RJ0155, and NASA NAG5-1599. This paper is JISAO Contribution Number 352 .

\section{APPENDIX A}

\section{Electra PMS Data Processing}

The Particle Measuring System Inc. 2D precipitation monoprobe consists of a 2D array of diodes illuminated by a $\mathrm{He}-\mathrm{Ne}$ laser. A particle passing through the probe measuring volume will occult diodes in the array. A photodiode is registered as shadowed when its output changes by $50 \%$. The set of shadowed states for the diodes within the 2D array forms a 2D image of each particle. This information is stored by the Electra PMS data system at a rate of $3 \times 10^{4}$ images per second (Baumgardner 1989).

Particle images from the Electra PMS were converted to drop spectra following Black and Hallet (1986). Black performed quality control and developed the processing methodology for the Electra PMS data in TOGA COARE. Images whose largest dimension was within the diode array were sized by the equivalent circle diameter-the diameter of a circle with the same area as the particle. Images that had their longest dimension on the diode array edge were counted as fractional particles, defined as the area of the image divided by the area of the circle of diameter equal to the length of the longest dimension. Images that occulted both end diodes were rejected. Zero-area events were recorded when a small particle whose size is on the same order as the size of the probe resolution $(0.2 \mathrm{~mm})$ tripped the probe into a ready state but passed completely across the probe before the next clock cycle of the imaging array occurred. These blank images created by real particles were treated as particles with a diameter of $0.16 \mathrm{~mm}$. A correction to the area was made to account for the stripping off of the first slice in each image by the particle probe recorder.

\section{APPENDIX B}

\section{Convective-Stratiform Separation Algorithm}

The convective-stratiform separation algorithm works by classifying regions of local $2 \mathrm{D}$ peakedness in the horizontal reflectivity field as convective and the remaining reflectivity echo greater than $15 \mathrm{dBZ}$ as stratiform. This methodology has been verified as consistent with the vertical velocity definition of convective versus stratiform by use of dual-Doppler vertical velocity data (Steiner et al. 1995). The separation algorithm can be applied within ranges from the radar where the Cartesian gridpoint resolution of $2 \mathrm{~km}$ is larger or approximately equal to the horizontal beamwidth of the radar. We applied the algorithm out to the $120-\mathrm{km}$ range, where the $1.1^{\circ}$ horizontal beamwidth of the LF radar was $2.3 \mathrm{~km}$.

Convective cell region centers are identified when the difference $\left(\Delta Z_{\mathrm{bg}}\right)$ between the reflectivity of an individual grid point and the local background reflectivity (the average of the radar reflectivity factor of nonzero radar echoes within a radius of $11 \mathrm{~km}$ around the grid point) exceeds a convective center criterion $\left(\Delta Z_{\mathrm{cc}}\right.$; Churchill and Houze 1984; Steiner et al. 1995). Once the convective centers have been identified, grid points within a certain radius of the convective center are classified as convective. We used the radii from Steiner et al. (1995), which are a function of background reflectivity. However, we had to modify their convective center criteria slightly to work with NOAA P-3 LF radar reflectivity data interpolated to $2 \mathrm{~km} \times 2 \mathrm{~km}$ resolution, as opposed to the ground-based radar data on which the algorithm was originally developed. Thus, the algorithm has to be "tuned" for the particular sensor collecting the data. To make the adjustment of the algorithm parameters more intuitive, the convective center criteria were changed to a cosine function of the form 


$$
\Delta Z_{\mathrm{cc}}=a \cos \left(\frac{1}{b} \frac{\pi Z_{\mathrm{bg}}}{2}\right) .
$$

This function has the same basic shape as the function used by Steiner et al. (1995). However, (B1) is continuous and easily adjusted by setting the parameters $a$ and $b$. When the aircraft was flying below $1-\mathrm{km}$ altitude and intersection of the $4^{\circ}$ vertical beam with the bright band at close ranges was geometrically infeasible, an additional criterion of a threshold intensity value $\left(Z_{\mathrm{ti}}\right)$ was applied. Thus, if the aircraft was below $1-\mathrm{km}$ altitude and if the reflectivity of the pixel was at least $Z_{\mathrm{t}}$, it was also labeled as a convective center.

The algorithm was tuned by setting $a, b$, and $Z_{\mathrm{ti}}$ such that the resulting objective classifications of the LF reflectivity map into convective and stratiform were most consistent with a subjective classification of precipitation type using vertical cross sections of reflectivity and radial velocity from the NOAA P-3 tail radar. The idea of the tuning is to use the bright band and other evidence of uniformity in the horizontal as "truth" regarding the presence of stratiform precipitation. If the algorithm calls any precipitation of this type convective, it is deemed to be in error. Values of $a$ and $b$ are sought that will minimize this error. This method of tuning the algorithm to agree with the implied vertical velocity structure of the radar echo pattern is exactly the same procedure followed by Steiner et al. (1995). Tuning could only be done at ranges less than $40 \mathrm{~km}$ from the aircraft since the X-band tail radar attenuated rapidly. At farther ranges, the conditions that can lead to misclassifications are lessened by the widening vertical beamwidth. Best results were found when $a=8, b=64$, and $Z_{\mathrm{ti}}=46$ $\mathrm{dBZ}$.

Tuning of the convective-stratiform separation algorithm is best accomplished with nearly instantaneous vertical cross sections. Storm evolution and motion will tend to obscure subtle features in the reflectivity field, such as a weak bright band, in data that are averaged over periods greater than $5 \mathrm{~min}$.

The algorithm had some difficulty distinguishing between embedded convection and heavy fallstreaks within stratiform regions. Sometimes these transitional regions were classified as convective and sometimes as stratiform. The transitional regions are typically difficult for objective algorithms to distinguish, and indeed it is often unclear from a subjective classification whether they should fall within the convective or stratiform classes. We tuned the algorithm such that transitional regions would tend to be labeled as stratiform rather than convective. This decision is based on the results of Yuter and Houze (1995b), in which statistical analysis of simultaneous high-resolution measurements of radar reflectivity and dual-Doppler vertical velocity showed that transitional regions, whose reflectivity pattern does not yet appear fully uniform in vertical cross sections, contain by volume predominately weak vertical air mo- tions that were stratiform in character. Although the verification of algorithm tuning was subjective, the algorithm performance was considered acceptable since it worked reasonably well over a wide variety of conditions observed during TOGA COARE.

\section{REFERENCES}

Atlas, D., P. Willis, and F. Marks, 1995: The effects of convective updrafts and downdrafts on reflectivity-rain rate relations and water budgets. Preprints, 27th Conf. on Radar Meteor., Vail, CO, Amer. Meteor. Soc., 19-22.

Austin, P. M., 1987: Relation between measured radar reflectivity and surface rainfall. Mon. Wea. Rev., 115, 1053-1070.

_ , and S. G. Geotis, 1979: Raindrop sizes and related parameters for GATE. J. Appl. Meteor., 18, 569-575.

Battan, L. J., 1973: Radar Observation of the Atmosphere. University of Chicago Press, 324 pp.

Baumgardner, D., 1989: Airborne measurements for cloud microphysics. Research Aviation Facility Bulletin 24, 22 pp. [Available from NCAR, P. O. Box 3000, Boulder, CO 80307.]

Best, A. C., 1952: The evaporation of raindrops. Quart. J. Roy. Meteor. Soc., 78, 200-225.

Black, R. A., and J. Hallett, 1986: Observations of the distribution of ice in hurricanes. J. Atmos. Sci., 43, 802-822.

Bond, G., and D. Alexander, 1994: TOGA COARE Meteorological Atlas. TOGA COARE International Project Office, $370 \mathrm{pp}$.

Braun, S. A., and R. A. Houze Jr., 1994: The transition zone and secondary maximum of radar reflectivity behind a midlatitude squall line: Results retrieved from Doppler radar data. J. Atmos. Sci., 51, 2733-2755.

- and - , 1996: The heat budget of a midlatitude squall line and implications for potential vorticity production. J. Atmos. Sci., 53, 1217-1240.

Calheiros, R. V., and I. Zawadzki, 1987: Reflectivity-rain rate relationships for radar hydrology in Brazil. J. Climate Appl. Meteor., 26, 118-132.

Churchill, D. D., and R. A. Houze Jr., 1984: Development and structure of winter monsoon cloud clusters on 10 December 1978. J. Atmos. Sci., 41, 933-960.

Corbet, J., C. Mueller, C. Burghart, K. Gould, and G. Granger, 1994: Zeb: Software for geophysical data integration, display, and management of diverse environmental datasets. Bull. Amer. Meteor. Soc., 75, 783-792.

Durden, S. L., E. Im, F. K. Li, W. Ricketts, A. Tanner, and W. Wilson, 1994: ARMAR: An airborne rain-mapping radar. J. Atmos. Oceanic Technol., 11, 727-737.

Fletcher, N. H., 1966: The Physics of Rainclouds. Cambridge University Press, $390 \mathrm{pp}$.

Friehe, C. A., S. P. Burns, D. Khelif, and X. Song, 1996: Meteorological and flux measurements from the NOAA WP3D aircraft in TOGA COARE. Preprints, Eighth Conf. on Air-Sea Interaction, Atlanta, GA, Amer. Meteor. Soc., 42-45.

Gamache, J. F., and R. A. Houze Jr., 1983: Water budget of a mesoscale convective system in the Tropics. J. Atmos. Sci., 40, 1835-1850.

Gunn, R., and G. D. Kinzer, 1949: The terminal velocity of fall for water droplets in stagnant air. J. Meteor., 6, 243-248.

Hauser, D., and P. Amayenc, 1983: Exponential size distributions of raindrops and vertical air motions deduced from vertically pointing Doppler data using a new method. J. Climate Appl. Meteor., 22, 407-418.

Hildebrand, P. H., C. A. Walther, C. L. Frush, J. Testud, and F. Baudin, 1994: The ELDORA/ASTRAIA airborne Doppler weather radar: Goals, design, and first field tests. Proc. IEEE, 82, 1873-1890.

Hobbs, P. V., S. Chang, and J. D. Locatelli, 1974: The dimensions and aggregation of ice crystals in natural clouds. J. Geophys. Res., 79, 2199-2206. 
Houghton, H. G., 1968: On precipitation mechanisms and their artificial modification. J. Appl. Meteor., 7, 851-859.

Houze, R. A., 1989: Observed structure of mesoscale convective systems and implication for large-scale heating. Quart. J. Roy. Meteor. Soc., 115, 425-461.

— 1993: Cloud Dynamics. Academic Press, 573 pp.

- , and D. D. Churchill, 1987: Mesoscale organization and cloud microphysics in a Bay of Bengal depression. J. Atmos. Sci., 44, $1845-1867$.

Hu, Z., and R. C. Srivastava, 1995: Evolution of raindrop size distribution by coalescence, breakup, and evaporation: Theory and observations. J. Atmos. Sci., 52, 1761-1783.

Hudlow, M. D., 1979: Mean rainfall patterns for the three phases of GATE. J. Appl. Meteor., 18, 1656-1669.

Huggel, A., W. Schmid, and A. Waldvogel, 1996: Raindrop size distributions and the radar bright band. J. Appl. Meteor., 35, 16881701

Joss, J., and A. Waldvogel, 1967: Ein Spectrograph für Niederschlagstropfen mit automatischer Auswertung. Pure Appl. Geophys., 68, 240-246.

Kucera, P. A., and Coauthors, 1995: COARE IOP rainfall from shipborne radars: 2. Analysis and comparison of gridded fields. Preprints, 27th Conf. on Radar Meteor., Vail, CO, Amer. Meteor. Soc., 681-683.

Leary, C. A., 1984: Precipitation structure of the cloud clusters in a tropical easterly wave. Mon. Wea. Rev., 112, 313-325.

Levin, Z., G. Feingold, S. Tzivion, and A. Waldvogel, 1991: The evolution of raindrop spectra: Comparisons between modeled and observed spectra along a mountain slope in Switzerland. $J$. Appl. Meteor., 30, 893-900.

Lilly, D. K., 1988: Cirrus outflow dynamics. J. Atmos. Sci., 45, 1594 1605.

List, R., and J. R. Gillespie, 1976: Evolution of raindrop spectra with collision-induced breakup. J. Atmos. Sci., 33, 2007-2013.

Locatelli, J. D., and P. V. Hobbs, 1974: Fall speeds and masses of solid precipitation particles. J. Geophys. Res., 79, 2185-2197.

Mapes, B. E., and R. A. Houze Jr., 1992: Satellite-observed cloud clusters in the TOGA COARE domain. TOGA Notes, April, 57.

— mesoscale convective systems. J. Atmos. Sci., 52, 1807-1828.

Mason, B. J., and R. Ramanadham, 1954: Modification of the size distribution of falling raindrops by coalescence. Quart. J. Roy. Meteor. Soc., 80, 388-394.

May, P. T., and D. K. Rajopadhyaya, 1996: Wind profiler observations of vertical motion and precipitation microphysics of a tropical squall line. Mon. Wea. Rev., 124, 621-633.

Rappaport, E. N., 1982: Structure and dynamics of an atypical tropical squall-line system M.S. thesis, Dept. of Atmospheric Sciences, University of Washington, $266 \mathrm{pp}$. [Available from University Microfilms, 300 N. Zeeb Road, Ann Arbor, MI 48103.]

Rigby, E. C., J. S. Marshall, and W. Hitschfeld, 1954: The devel- opment of the size distribution of raindrops during their fall. $J$. Meteor., 11, 362-372.

Rosenfeld, D., D. Atlas, D. B. Wolff, and E. Amitai, 1992: Beamwidth effects on $Z-R$ relations and area-integrated rainfall. J. Appl. Meteor., 31, 454-464.

— D. B. Wolff, and D. Atlas, 1993: General probability-matched relations between radar reflectivity and rain rate. J. Appl. Meteor., 32, 50-72.

Rousseuw, P. J., and A. M. Leroy, 1987: Robust Regression and Outlier Detection. Wiley and Sons, 329 pp.

Short, D. A., T. Kozu, and K. Nakamura, 1990: Rain rate and raindrop size distribution observations in Darwin Australia. Proc. URSI Commission F Open Symp. on Regional Factors in Predicting Radiowave Attenuation Due to Rain, Rio de Janeiro, Brazil, International Union of Radio Science Commission, 35-40.

Smith, P. L., Z. Liu, and J. Joss, 1993: A study of sampling variability effects in raindrop size observations. J. Appl. Meteor., 32, 12591269.

Steiner, M., and R. A. Houze Jr., 1997: Sensitivity of the estimated monthly convective rain fraction to the choice of $Z-R$ relation. J. Appl. Meteor., 36, 452-462.

, - - and S. E. Yuter, 1995: Climatological characterization of three-dimensional storm structure from operational radar and rain gauge data. J. Appl. Meteor., 34, 1978-2007.

Tokay, A., and D. A. Short, 1996: Evidence from tropical raindrop spectra of the origin of rain from stratiform versus convective clouds. J. Appl. Meteor., 35, 355-371.

Waldvogel, A., 1974: The $N_{\mathrm{o}}$ jump in raindrop spectra. J. Atmos. Sci., 31, 1067-1078

- W. Henrich, and W. Schmid, 1995: Raindrop size distributions and radar reflectivity profiles. Preprints, 27 th Conf. on Radar Meteor., Vail, CO, Amer. Meteor. Soc., 26-28.

Webster, P. J., and R. Lukas, 1992: TOGA COARE: The Coupled Ocean-Atmosphere Response Experiment. Bull. Amer. Meteor. Soc., 73, 1377-1416.

Willis, P. T., R. A. Black, and F. D. Marks Jr., 1995: Airborne rain drop size distributions in TOGA COARE. Preprints, 21th Conf. on Hurricanes, Miami, FL, Amer. Meteor. Soc., 431-433.

Yuter, S. E., and R. A. Houze Jr., 1995a: Three-dimensional kinematic and microphysical evolution of Florida cumulonimbus. Part I: Spatial distribution of updrafts, downdrafts, and precipitation. Mon. Wea. Rev., 123, 1921-1940.

— physical evolution of Florida cumulonimbus. Part II: Frequency distributions of vertical velocity, reflectivity, and differential reflectivity. Mon. Wea. Rev., 123, 1941-1963.

, and - 1995c: Three-dimensional kinematic and microphysical evolution of Florida cumulonimbus. Part III: Vertical mass transport, mass divergence, and synthesis. Mon. Wea. Rev., 123, 1964-1983.

, B. F. Smull, F. D. Marks Jr., J. R. Daugherty, and S. R. Brodzik, 1995: TOGA COARE aircraft mission summary images: An electronic atlas. Bull. Amer. Meteor. Soc., 76, 319328 